\title{
ENVIRONMENTAL QUALTTY INFORMATION ANALYSIS CENTER MULTI-YEAR PLAN
}

Rafael G. Rivera, RDG, Inc. Sujit Das, Oak Ridge National Laboratory Thomas E. Walsh, University of Florida

Date Published: September 1992

Prepared for the U.S. Air Force Air Force Civil Engineering Support Agency

Tyndall Air Force Base, Florida

\author{
Prepared by the \\ Oak Ridge National Laboratory \\ Oak Ridge, Tennessee 37831 \\ managed by \\ MARTIN MARIETTA ENERGY SYSTEMS, INC. \\ for the \\ U.S. DEPARTMENT OF ENERGY \\ under contract DE-ACOS-84OR21400
}

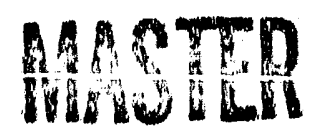




\section{CONTENTS}

LIST DF TABLES/FIGURES $\ldots \ldots \ldots \ldots \ldots \ldots \ldots \ldots \ldots \ldots \ldots \ldots$

EXECUTIVE SUMMARY $\ldots \ldots \ldots \ldots \ldots \ldots \ldots \ldots \ldots \ldots \ldots \ldots \ldots \ldots \ldots$

1. INTRODUCTION $\ldots \ldots \ldots \ldots \ldots \ldots \ldots \ldots \ldots \ldots \ldots \ldots \ldots \ldots \ldots \ldots$

1.1 PURPOSE AND SCOPE OF DOCUMENT $\ldots \ldots \ldots \ldots \ldots \ldots \ldots \ldots \ldots \ldots 1$

1.2 IMPORTANCE OF ENVIRONMENTAL TECHNOLOGY INFORMATION 1

1.3 ENVIRONMENTAL TECHNOLOGY AREAS ................. 2

1.4 CATEGORIES OF ENVIRONMENTAL QUALITY INFORMATION AND

ANALYSIS NEEDS $\ldots \ldots \ldots \ldots \ldots \ldots \ldots \ldots \ldots \ldots \ldots \ldots \ldots \ldots$

1.4.1 Need for a Systems Approach to Environmental Technology Issues ..... 3

1.4.2 Deficiencies in the Quality of Existing Environmental Technology

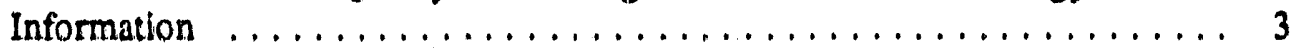

1.4.3 User Requirements for Environmental Quality Information ......... 4

1.4.4 Categories of Information In Demand .................. 5

1.4.4.1 Near-Term Decision Support (Technology Information and

Analysis for Logistical Operations) $\ldots \ldots \ldots \ldots \ldots \ldots \ldots$

1.4.4.2 Long-Term Decision Support (Technology Information for

Program Planning, Budgeting, and Technology Acquisition) ... 6

1.5 AIR FORCE NEEDS FOR ENVIRONMENTAL QUALITY

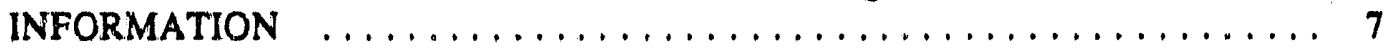

1.5.1 Environmental Quality Program Goals ................... 7

1.5.2 Environmental Technology Areas $\ldots \ldots \ldots \ldots \ldots \ldots \ldots \ldots \ldots$

1.5.3 Categories of Information ...................... 9

1.5.4 An Approach to Meeting Technology Information Needs .......... 10

1.6 OUTLINE OF MULTI-YEAR PLAN $\ldots \ldots \ldots \ldots \ldots \ldots \ldots \ldots \ldots \ldots$

2. REVIEW OF COMPARABLE EXISTING IACs $\ldots \ldots \ldots \ldots \ldots \ldots \ldots \ldots \ldots 13$

2.1 INFORMATION ANALYYSIS CENTER HISTORY $\ldots \ldots \ldots \ldots \ldots \ldots \ldots 13$

2.2 SUMMARY OF INFORMATION ANALYYSIS CENTERS REVIEWED $\ldots .14$

2.3 ISSUES THAT NEED TO BE CONSIDERED FOR IAC DEVELOPMENT 16

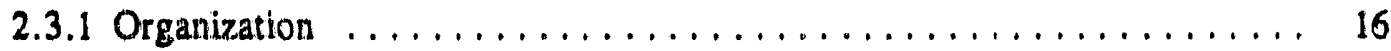

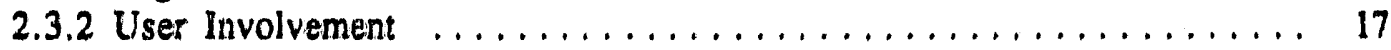

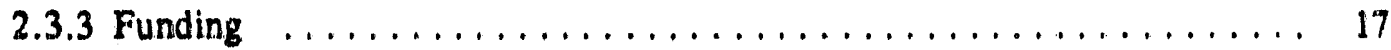

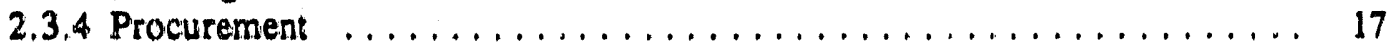

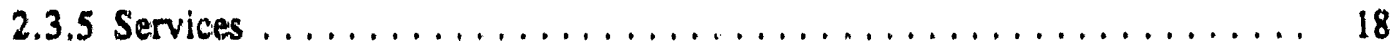

2.3.6 Reimbursement of Services ..................... 18

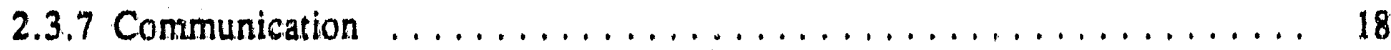

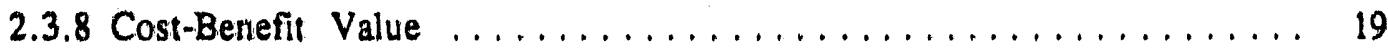

3. MISSION AND STRATEGIC OBJECTIVES $\ldots \ldots \ldots \ldots \ldots \ldots \ldots \ldots \ldots \ldots$

3.1 THE EQIAC MISSION $\ldots \ldots \ldots \ldots \ldots \ldots \ldots \ldots \ldots \ldots \ldots \ldots \ldots \ldots \ldots \ldots$

3.2 EQIAC STRATEGIC OBJECTIVES $\ldots \ldots \ldots \ldots \ldots \ldots \ldots \ldots \ldots \ldots \ldots$

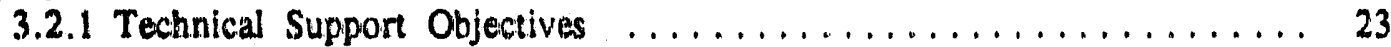

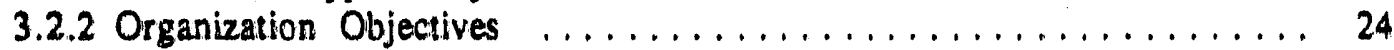

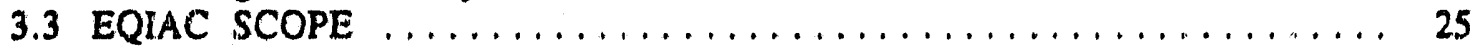


4. EQIAC DESCRIPTION ........................... 27

4.1 ORGANIZATIONAL PHILOSOPHY - NODAL APPROACH ....... 27

4.2 EQIAC ORGANIZATIONAL STRUCTURE $\ldots \ldots \ldots \ldots \ldots \ldots \ldots, 27$

4.2.1 Phase 1: Initial Operational Capability ................. 29

4.2.2 Phase 2: Intermediate Operational Capability $\ldots \ldots \ldots \ldots \ldots \ldots, 32$

4.2.3 Phase 3: Full Operational Capability ................. 32

4.2.4 Specific Recommendations for Phase 1 Development: Air Force Operations $\ldots \ldots \ldots \ldots \ldots \ldots \ldots \ldots \ldots \ldots \ldots \ldots \ldots \ldots, 32$

4.3 MULTT-AGENCY COORDINATION $\ldots \ldots \ldots \ldots \ldots \ldots \ldots \ldots \ldots, 34$

4.4 THE FUNDING PLAN FOR EQIAC $\ldots \ldots \ldots \ldots \ldots \ldots \ldots \ldots \ldots \ldots \ldots$

4.5 REVENUES FROM EQIAC PRODUCTS AND SERVICES $\ldots \ldots \ldots \ldots \quad 35$

5. SYSTEM REQUIREMENTS $\ldots \ldots \ldots \ldots \ldots \ldots \ldots \ldots \ldots \ldots \ldots \ldots, 37$

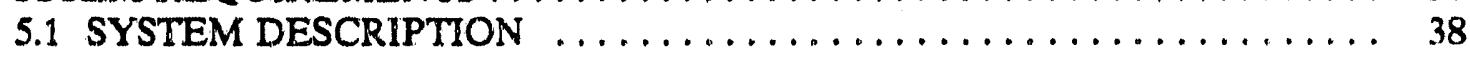

5.1.1 Phase 1 (Initial Operational Capability) $\ldots \ldots \ldots \ldots \ldots \ldots \ldots \ldots, 38$

5.1 .1 .1 Hardware $\ldots \ldots \ldots \ldots \ldots \ldots \ldots \ldots \ldots \ldots \ldots \ldots, 40$

5.1.1.2 Software $\ldots \ldots \ldots \ldots \ldots \ldots \ldots \ldots \ldots \ldots \ldots \ldots, 41$

5.1.2 Phase 2 (Intermediate Operational Capability) ............. 41

5.1.2.1 Hardware $\ldots \ldots \ldots \ldots \ldots \ldots \ldots \ldots \ldots \ldots \ldots \ldots, 41$

5.1.2.2 Software $\ldots \ldots \ldots \ldots \ldots \ldots \ldots \ldots \ldots \ldots \ldots \ldots, 41$

5.1.3 Phase 3 (Full Operational Capability) $\ldots \ldots \ldots \ldots \ldots \ldots \ldots \ldots, 42$

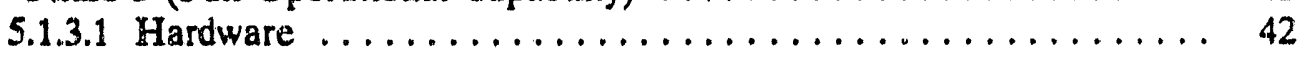

5.1 .3 .2 Software $\ldots \ldots \ldots \ldots \ldots \ldots \ldots \ldots \ldots \ldots \ldots, 42$

6. PROJECTED EQIAC COSTS $\ldots \ldots \ldots \ldots \ldots \ldots \ldots \ldots \ldots \ldots \ldots \ldots \ldots . \ldots \ldots$

6.1 COSTS OF EQIAC OPERATION $\ldots \ldots \ldots \ldots \ldots \ldots \ldots \ldots \ldots, 43$

6.1 .1 Labor Costs $\ldots \ldots \ldots \ldots \ldots \ldots \ldots \ldots \ldots \ldots \ldots \ldots, 43$

6.1.2 Nonlabor Costs $\ldots \ldots \ldots \ldots \ldots \ldots \ldots \ldots \ldots \ldots \ldots \ldots, 46$

7. SUMMARY AND RECOMMENDATIONS $\ldots \ldots \ldots \ldots \ldots \ldots \ldots \ldots, 49$

7.1 SUMMARY OF THE EQIAC PLAN $\ldots \ldots \ldots \ldots \ldots \ldots \ldots \ldots \ldots \ldots, 49$

7.2 GENERAL RECOMMENDATIONS .................... 50

7.3 RECOMMENDATIONS FOR AN INITIAL AIR FORCE EQIAC ...... 51

APPENDIX A: A REVIEW OF EXISTING IACs $\ldots \ldots \ldots \ldots \ldots \ldots \ldots \ldots, 53$

APPENDIX B: EXAMPLES OF ENVIRONMENTAL TECHNOLOGY

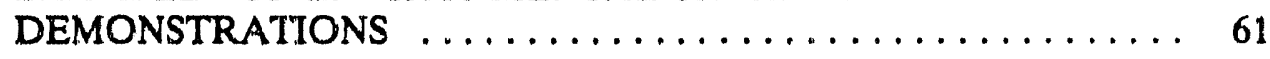

APPENDIX C: REFERENCES $\ldots \ldots \ldots \ldots \ldots \ldots \ldots \ldots \ldots \ldots \ldots \ldots \ldots \ldots \ldots \ldots$

APPENDIX D: ORGANIZATIONS CONTACTED FOR EQIAC PLAN INPUT $\ldots 73$ 


\section{TABLES}

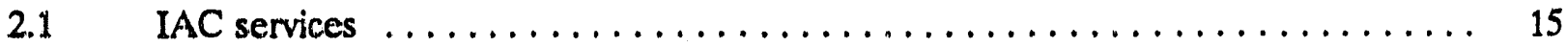

3.1 Information demand and services supply matrix $\ldots \ldots \ldots \ldots \ldots \ldots \ldots \ldots$

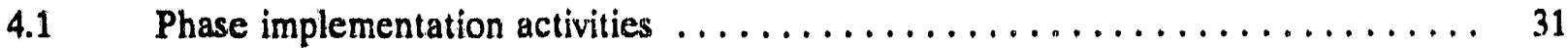

$5.1 \quad$ EQIAC system requirements $\ldots \ldots \ldots \ldots \ldots \ldots \ldots \ldots \ldots \ldots \ldots \ldots \ldots \ldots$

6.1 EQIAC operational cost projections $\ldots \ldots \ldots \ldots \ldots \ldots \ldots \ldots \ldots \ldots \ldots$

$6.2 \quad$ Staff and labor projections $\ldots \ldots \ldots \ldots \ldots \ldots \ldots \ldots \ldots \ldots \ldots \ldots \ldots$

6.3-A Acquisition costs of EQIAC hardware and software - Phase $1 \ldots \ldots \ldots$

6.3-B Acquisition costs of EQIAC hardware and software - Phase 2

\section{FIGURES}

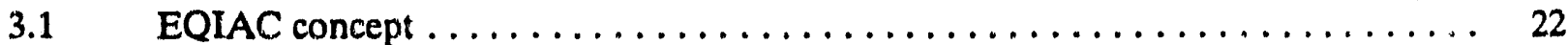

4.1 Examples of EQIAC distributed technology nodes $\ldots \ldots \ldots \ldots \ldots \ldots \ldots \ldots$

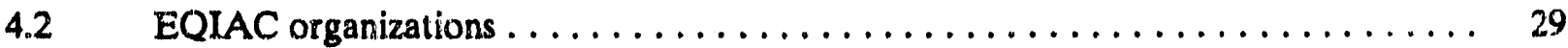

$5.1 \quad$ EQLAC communication network $\ldots \ldots \ldots \ldots \ldots \ldots \ldots \ldots \ldots \ldots \ldots \ldots$

6.1 PROJECTED EQIAC operations cost FY-1992 through FY-1994 $\ldots \ldots \ldots \ldots$ 


\section{EXECUTTVE SUMMARY}

\section{BACKGROUND}

An information analysis center (IAC) is a federal resource that provides technical information for a specific technology field. An IAC links an expert technical staff with an experienced information specialist group, supported by in.house or external data bases to provide technical information and maintain a corporate knowledge in a technical area. An IAC promotes the rapid transfer of technology among its users and provides assistance in adopting new technology and predicting and assessing emerging technology.

This document outlines the concept, requirements, and proposed development of an Environmental Quality IAC (EQIAC). An EQIAC network is composed of several nodes, each of which has specific technology capabilities. This document outlines strategic and operational objectives for the phased development of one such node of an EQIAC network. It also makes recommendations for developing and implementing an initial EQIAC node within the U.S. Air Force and uses this Air Force case study to develop operational requirements and cost estimates for an EQIAC node.

\section{THE NEED}

Costs for environmental cleanup-related goods and services have increased over the past decade, partly because of increased technology costs for remediation and for facility waste operations. Federal agencies have a mission to carry out environmental cleanup and compliance. Technology is an important factor in those activities because it can help agencies comply with environmental requirements at a lower cost. As a result, demand is growing for available technology alternatives for solving environmental problems and for research and development $(R \& D)$ in areas where practical solutions do not exist.

The demand for technologies is in four areas of environmental operations:

- Site restoration. The requirements for site restoration include, but are not limited to, technologies for treatment, removal, and/or containment of contaminated areas of a facility.

- Pollution control. Pollution control technologies may include processes that reduce or eliminate environmental emissions to atmosphere, water, and land.

- Hazardous waste minimization. Complementary to pollution control technologies are technologies to reduce hazardous wastes, and many other types of industrial wastes.

- Contaminant fate and site characterization. Environmental operations demand advanced systems, methods, and technologies for predicting the fate and transport of pollutants and integrated information gathering-technology systems for monitoring, characterization, and control of pollutants. 
Technology information is needed for:

- Near-term decision support (technology information and analysis for logistical operations). This support includes identifying and assessing the most appropriate technologies and methods for addressing environmental issues on a "real-time" basis, including technologies for characterizing the environmental condition of $a$ facility.

- Long-term decision support (technology information for program planning, budgeting, and technology acquisition). This support includes identifying, defining, and validating tectnologies, information, and technical assistance to help define and identify the future environmental requirements of research, development, and acquisition programs.

\section{THE EQIAC MISSION}

EQIAC's mission is to serve as an authoritative, full-service center providing information, technical expertise, and analysis capabilities in environmental quality technology to support federal environmental operations. A systems approach (including analyses of economic and institutional issues) to characterization and analysis of the problem is used to optimize a particular solution and to understand fully the conditions for applying that solution at other sites. In the Air Force case, EQIAC's initial emphasis will be on analysis to support developers and planners in the research, development, and acquisition organization.

\section{THE EQIAC STRATEGIC OBJECTTVES}

The principal objective of the EQIAC is to collect, substantiate, analyze, and disseminate scientific and technical information on environmental quality. A second objective is to maintain and/or access data bases and serve as a collection and dissemination point for environmental technology applications. A third objective is to be the focal point for the transfer of environmental quality technology to federal environmental research, development, demonstration, and field operations.

Strategic objectives to carry out the mission of the EQIAC include the development of resources, capabilities, and an operational structure. The strategic objectives of the EQIAC are:

1. Development of technical capability: To develop the capability and resources to provide technology-based information, technical analysis and assessment, and referral and training support to clients.

2. Organization development: To develop and maintain a technically preeminent and fiscally viable organization able to respond to demands and challenges effectively with a solid technical and administrative structure.

In the Air Force case, an additional objective is to focus on R\&D of new technology to meet current and future Air Force needs. 'This objective will result in concentration on clients that include researchers, program developers, and planners. 


\section{THE EQIAC ORGANIZATION}

The "nodal" approach to establishing an EQIAC would involve developing several IACs focused on specific environmental technologies and/or technical support services. These "mini" EQIACs would form a distributed nodal network. For example, one EQIAC node might concentrate on chemical treatment technologies for site restoration and offer technical support for characterizing sites and applying technologies. Other EQIAC nodes might concentrate on technologies such as pollution prevention and bioremediation. These nodes would be located at facilities that have expertise in specific types of technologies: universities, national laboratories, and federal and private organizations.

The planned Air Force EQIAC will exist within the Air Force Civil Engineering Support Agency (AFCESA) at Tyndall Air Force Base, Florida, as a unit within the AFCESA/Research and Acquisition planning office. The program manager and director will establish the overall goals of the EQIAC and provide leadership in the interfaces with the command structure and the interagency coordination. The EQIAC director will manage the distribution of EQIAC resources among the various tasks being processed. Teams will be formed from the personnel of the two principal units, information services and analytical services, and assigned to the various tasks.

EQIAC implementation will be accomplished in three phases: (1) the initial operational capability scheduled for the fourth quarter of 1992; (2) the intermediate operational capability scheduled for the second quarter of 1993, during which the organization will grow significantly to a total staff of sixteen; and (3) the full operational capability in December 1994.

\section{RECOMMENDATIONS}

This study results in the four recommendations below. It is clear that the need of federal agencies for environmental technology information is not being met effectively. A multi-agencysupported EQIAC organization could meet that need, avoid duplication of effort, and facilitate the use of the most appropriate and cost-effective technology for a specific environmental situation. The recommendations are:

1. A multi-agency-supported, national center for the technical support, diagnosis, and systems analysis of environmental problems and for the management, assessment, and distribution of environmental quality technology information should be established by a federal agency or as a multi-agency consortium.

2. This center should coordinate all federal environmental technology information sources and develop an effective network to access, maintain, and distribute environmental technology information in a timeframe necessary to meet federal environmental operational requirements.

3. The center should focus on coordinating and/or supporting the developmen methodologies and systems to characterize and analyze environmental site problems : nd to support technology information needs for planning and analyzing federal ag uncies' environmental program requirements. 
4. The center should be developed incrementally by technology demand area and according to a phased organizational approach that allows for controlled growth. It should be developed in a manner most responsive to federal agencies' needs. 


\section{INTRODUCTION}

An information analysis center (IAC) is a federal resource that provides technical information for a specific technology field. An IAC links an expert technical staff with an experienced information special ist group, supported by in-house or external data bases to provide technical information and maintain a corporate knowledge in a technical area. An IAC promotes the rapid transfer of technology among its users and provides assistance in adopting new tecl-nology and predicting and assessing emerging technology.

The Environmental Quality Information Analysis Center (EQIAC) is similar to a technology-oriented IAC. Its purpose is to provide technical information on a quick-response basis about key environmental issues such as restoration of contaminated installations, prevention of pollution, compliance, and waste minimization. A framework of tools and models supports its analytical systerns approach to problem solving.

\subsection{PURPOSE AND SCOPE OF DOCUMENT}

This document outlines the concept, the requirements, and the proposed development of an EQIAC. It makes recommendations for establishing an EQIAC using a phased approach. Its recommendations are based on a review of various agencies' needs for environmental technology information to meet compliance and restoration requirements. Given the evolving nature of the EQIAC concept and the continual identification of additional environmental requirements and resources, this must be considered a living document subject to continuous updating.

This document attempts to address the generic nature of federal agencies' needs for technology information: Most agencies need similar types of information to satisfy environmental regulations. However, although this EQIAC could be implemented by any federal agency, the plan was developed at the Air Force Civil Engineering Support Agency (AFCESA) using the operational needs and cost estimates of the U.S. Air Force. This approach is used because of the Air Force's interest in such a support organization and because it provides a real-life case study for developing costs and staffing requirements.

It is the intent of this document to provide sufficient information about the development of the EQIAC at the AFCESA to enable any other federal agency to formulate a multi-year plan for setting up an EQIAC to meet its own needs.

\subsection{IMPORTANCE OF ENVIRONMENTAL TECHNOLOGY INFORMATION}

Costs for cleanup-related goods and services have increased over the past decade partly because of the increase in technology costs for remedial operations and facility waste management operations. Conventional technologies for remediating complex sites are not only complex and costly, but also in most cases inadequate to achieve cleanup and compliance goals. Therefore, federal agencies must continually identify areas where available technologies are inadequate and develop more effective, less costly means of satisfying long- and short-term regulatory requirements and public expectations. The need is growing for available alternative technical solutions to environmental problems and for research and development (R\&D) in areas where practical approaches are unavailable. 
Effective and efficient environmental technology provides a variety of benefits, including reduced costs and risks, and it results in lower environmental impact. The U.S. Department of Energy (DOE) has concluded that some DOE sites cannot be restored without fundamental changes in cleanup technology. To meet their technology needs, federal agencies such as DOE, the Environmental Protection Agency (EPA), and the three Department of Defense (DoD) services have embarked on complementary efforts to develop more cost-effective environmental technologies. These efforts include improved drilling; in situ characterization; improved decontamination and decommissioning technologies; and treatment technologies for soils, waste sites, and groundwater. All federal agencies will realize the benefits of this improved technology. All agencies have a mission to accomplish environmental compliance and cleanup, and more effective and appropriate technologies will allow them to accomplish that mission at lower cost.

\subsection{ENVIRONMENTAL TECHNOLOGY AREAS}

Environmental technologies cover a broad spectrum from genetically engineered bacteria to mechanical systems for washing soils. Technologies are being developed to address a large variety of wastes created by federal agencies; chemical, biological, and radioactive contamination; and soil, water, and atmospheric pollution. Appendix B provides examples of technologies currently being demonstrated. These technologies apply to four areas of environmental operations where improved technology is needed:

- Site restoration. The technology requirements for site restoration include but are not limited to technologies for treatment, removal, and/or containment of contaminated areas of a facility. Treatment technologies may include bioventing for soil cleanup; catalytic oxidation, biological and chemical technologies for site remediation; biotechnologies for treatment of organics and ground water cleanup; and technologies for deep soil decontamination. Technologies for removal and/or containment may include robotics, insitu processing systems, in situ vitrification, and removal or neutralizing technologies such as for asbestos removal.

- Pollution control. Pollution control technology may include processes that reduce or eliminate environmental emissions to atmosphere, water, and land. Examples may inciude technologies for air toxics and volatile organic compounds emissions, reduction of $\mathrm{NO}_{\mathrm{x}}$, sensors and monitors, advanced integrated contaminant transport models, and other technologies dealing with atmospheric chemistry and with effluents of new solvents and cleaners.

- Hazardous waste minimization. Complementary to pollution control technologies, technologies for reducing hazardous waste may include nonhazardous alternatives to electroplating, nonhazardous cleaners, degreasers, and strippers, treatment of metal bearing wastes, degradation of solid rocket propellent, and many other processing technologies to minimize many other types of wastes.

- Contaminant fate and site characterization. These technologies include advanced systems, methods, and technologies for predicting the fate and trarsport of pollutants and integrated information gathering technologies and systems for monitoring, characterization, and control. 
Although there is some overlap in this definition of technology categories, segmentation in these technology areas allows for a controlled approach to managing technology and developing the capability to address environmental technology issues.

\subsection{CATEGORIES OF ENVIRONMENTAL QUALITY INFORMATION AND ANALYSIS NEEDS}

Technology to comply with environmental quality requirements is developing and changing rapidly. In most cases, the environmental technology information available to field personnel is not current because of the way technology filters through the deployment (commercialization) process to the end-user. There exists a need for a real-time environmental technology resource center to assist in the development of methodologies and integrated frameworks for systems analysis of environmental issues and to promote technology transfer by providing the latest environmental technology information.

An entity for environmental technology information not only can address those needs but also can provide the "corporate memory" that allows increased efficiency in program development and field operations; avoid duplication of effort; and ensure quality by identifying technologies and providing information on those that are either nonverifiable or incomplete. For example, each federal agency engaged in environmental compliance activities has information systems for environmental activities or technology information. An environmental quality information center is necessary to make those resources available to others. Scientific and technical exchange among the developers of those systems will enhance their quality, thereby improving the quality of information available to users.

\subsubsection{Need for a Systems Approach to Environmental Technology Issues}

Every agency must comply with federal environmental requirements in pollution control, hazardous waste management, and site restoration. Although many problems are similar at different sites, the approach to addressing specific environmental issues may differ. A systems approach to characterizing and analyzing the problem is necessary to optimize a particular solution and to understand fully the conditions for applying that solution at other sites.

An environmental problem needs to be considered as specific sub-problems - from site characterization to final assessments of remediation activity. For each specific sub-problem, analytical capabilities to include all important factors such as economic and institutional issues are needed to consider questions such as the clean-up criteria; the extent to which the proposed technology meets the regulatory requirements; and cost-benefit trade-offs among available alternatives. A "one-stop" systems analysis capability is needed that can develop and apply methodologies to characterize a problem "from cradle to grave." This "systems modeling" of a site's environmental characteristics will assist in identifying the reasons for a problem and thereby in identifying areas for existing technology application and future technology needs.

\subsubsection{Deficiencies in the Quality of Existing Environmental Technology Information}

Deficiencies in the type, amount, and quality of available environmental technology information have been indicated by organizations such as DOE, EPA, and DoD. Although each organization has different needs derived from different applications, they all require access to 
the best technology information in site remediation, environmental compliance, and program development and planning. In particular, the technology information to conduct the following activities effectively is deficient:

1. Program planning. All organizations need to estimate and minimize the cost of program compliance. They need information on emerging technology and its applications, schedule of availability, applicability, and costs. Given the constraints in the available budget, only the most realistic, cost-effective technology options will allow agencies to meet their missions.

2. Remediation/restoration. Although remediation/restoration is a common need and much information exists in this area, more cost-effective technology is needed to meet mission requirements. Another particular area of need is "real-time" response to technology application problems-quick analysis and decisions and applicable technologies to address the problems.

3. Assessments and review. Although all organizations have extensive technical capabilities through their laboratory systems, there is a need for independent expert review and assessment of proposed technologies and actions and for quick advanced technology assessments that can be used for programmatic decision-making.

For example, although the DOE Office of Environmental Restoration and Waste Management (DOE/EM) is responsible for environmental technology development, restoration, and waste operations, its other offices such as the Office of Defense Programs and the Office of New Production Reactor have planning and operational responsibilities that require information about environmental technology availability, efficacy, and costs. Comparable to the DOE/EM Office of Technology Development, the EPA assistant administrator for research and development conducts research, development, and demonstration (RD\&D) projects on environmental and health technology. Other EPA organizations such as the assistant administrators for solid waste and emergency response, water, and air and radiation apply this information in field operations.

\subsubsection{User Requirements for Environmental Quality Information}

As a result of program reviews into research requirements and interviews with federal staff, the following have been identified as key types of information required by environmental decision-makers:

- technology availability;

- technology applications and efficacy;

- experience and acceptability of a technology for compliance requirements;

- $\quad$ sources and methods of application;

- experience in performance and reliability;

- costs and experienced sources;

- type and applicability of emerging and developmental technologies;

- environmental technology gaps and R\&D needs;

- assistance in understanding these technologies; and

- real-time response to operational technology information needs in the environmental field. 
Although some of this information exists and some is being generated by research with federal sponsorship, much of it is not readily available to federal agency program managers. Also, a review of existing IACs (see Sect. 2.0) indicates that these environmental technology information needs and analytical services are not being addressed by other LACs. Moreover, the current IACs do not encompass the rea'--time, quick response, and full technical service concept required by federal agencies.

\subsubsection{Categories of Information In Demand}

The demand for environmental technology information within federal agencies falls into two categories: near-te: $m$ or real-time support of operations, and lorg-term nieeds in R\&D and acquisition. These hwo demand categories are defined as follows:

- Near-term decision support (technology information and analysis for lopistical operations). This category includes identifying anci assessing the most appropriate technologu and methods to address environmental issues on a real-time basis, including technologies, information, methods, and lechnical assistance for characterining a facility.

- Long term decision support (technology information for program planning, budigeting, and technology acquisition). This category includes identifying, defining, and validating technologies and providing information and technical assistance to identify and define future environmental requirements of research, development, and acquisition (RD\&A) programs.

The latter category is required to provide the basic information needed for program planning and for developing and acquiring new systems and industrial progranns; restructuring and redirecting existing programs; and identifying technology $R \& D$ requirements and developing efficient, targeted R\&D programs to meet identified and projected environmentel technology needs.

The following examples illustrate technical analysis requirements in these two categories that could be supported by EQIAC resources.

\subsubsection{Near-Term Decision Support (Technology Information and Analysis for Logistical Operations)}

The field of environmental management has grown too quickly to allow for a thorough understanding of all relevant technological alternatives for solving environmental problems. Technologies to comply with environmental quality requirements are being developed, changed, and improved rapidly. Often federal personnel are not aware what technology, inethods, and tools are available to carry out a program. Moreover, the complexity and quality of the information available sometimes does not allow for the most appropriate and/or cost-effective decisions on procuring and using technology to resolve a specific problem.

These factors, along with staft turnover in environmental-related positions, result in a discontinuity of corporate knowledge. Also, environmental technology information available to 
field personnel often is dated and presents an inefficient way to resolve a problem. A system is needed to provide technology information and promote acceptable emerging technologies that might not otherwise be an option.

These near-term decision support requirements include:

- identification, assessment, and validation of technologies for sampling and measuring hazardous materirls in ground, air, and water and types and levels of contamination in animal and plant life;

- assessment of methods for quantifying environmental pollution, including simulation models of toxic contamination;

- monitoring of technology development and applications for identifying the type and quantifying the evaluation of related applications of emerging technology candidates; and

- assessment of available methods, models, and approaches for environmental impact analysis, including socio-economic analysis.

These and other operations-related environmental technology information were key needs identified by the operations staff interviewed.

\subsubsection{Long-Term Decision Support (Technology Information for Program Planning, Budgeting, and Technology Acquisition)}

The requirements for program planning and budgeting cut across all federal organizations. Program planning, budgeting, and technology acquisition either for new programs or for modernizing, improving, and restoring existing programs or facilities require a good estimate of the type and cost of technology investments needed for environmental compliance programs. Organizations responsible for developing technology and systems must be able to quantify the environmental impacts and compliance requirements for their specific development programs. Similarly, facility operations managers are responsible for complying with environmental requirements; those requirements can usually be met effectively only with new technologies.

For example, developing programs for new weapons systems and industrial processes or restructuring new facilities and mission operations all require estimating the cost of environmental compliance. Many of these programs may require or use new exotic technologies or materials with unknown environmental impacts; or there may be technology alternatives, developed and emerging, that could meet an environmental requirement more efficiently. In either case, assessing and validating available technology, including the costs and benefits of feasible alternatives, and identifying technological requirements to meet programmatic needs are key factors in program planning and budgeting.

Information needed for this type of long term decision support includes:

- assessing available technology to meet specific current and future environmental operations requirements, for example, treating chemicals and other toxics in maintenance and industrial processes; 

cost;

- assessing technology requirements of environmental compliance for program and/or new system, including estimating the cost of environmental technology development; and

- validating available technologies, tools, and methods for environmental compliance applications.

These requirements are fundamental to program planning and budgeting of $R \& D$ and/or facility development programs in all federal agencies.

\section{AIR FORCE NEEDS FOR ENVIRONMENTAL QUALTTY INFORMATION}

Environmental technology information requirernents within the Air Force are similar to those of other agencies. As a federal agency, the Air Force is the steward of federal resources: property, facilities, equipment, etc. Although defense operations generate requirements for technology for specialized treatment of substances such as rocket fuel, most of the remediation, restoration, pollution control, and other compliance requirements are similar to those of other agencies.

The Air Force environmental quality information needs for near-term analysis and decision support to meet operational needs are distributed throughout the Air Force but principally coordinated through the Air Force Center for Environmental Excellence (AFCEE) and the Environmental Consulting Services Division at Brooks Air Force Base, Texas. The information for program planning development and budgeting is focused on organizations (such as Air Force Systems Command, and AFCESA) conducting research, development, testing, and demonstration (RDT\&D). The development of advanced systems is where forecasting and assessing of environmental technology is most needed. In addition to RDT\&D, program planning and budgeting for new facility development, facility modernization, and facility and site restoration require environmental compliance plans that in turn require the identification of the best and most cost-effective technological options.

\subsection{Environmental Quality Program Goals}

Environmental quality is paramount in planning air base operations to meet the Air Force mission requirements. The Air Force strives to mitigate the environmental impact of weapon systems, comply with public law, and provide cost-effective cleanup and site restoration procedures for hazardous waste sites. Federal, state, and local environmental quality regulations enacted in recent years have increased in stringency and number. Stricter air quality standards, reduced hazardous waste discharge limits, prohibition of landfill disposal of hazardous wastes, and lower occupational exposure limits are the trends. Recent base closures have caused additional pressure on the Air Force Installation Restoration Program (IRP). The current IRP has identified more than 3600 sites contaninated from past practices and accidents. The estimated cost of remediating these sites is over $\$ 5$ billion. Most of the contamination results from 
practices that complied with the laws of their time. Without technology innovation, the Air Force faces severe environmental and occupational restrictions and high compliance costs for its military installations.

The Air Force needs technologies to meet its environmental, safety, and occupational health goals that include:

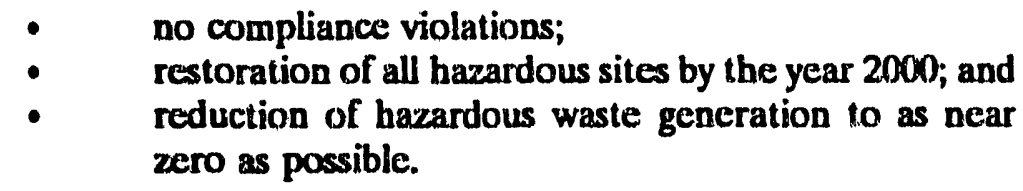

The technologies must support cleanup of past problems, compliance in present operations, and prevention of future problems. New environmental technology developments is crucial to mitigate hazards, particularly those related to high intensity noise, toxic chemicals, and electromagnetic radiations. The existing Air Force Technology Development program is based on processes that use existing or maturing technology to solve its current problems. This perspective recognizes the need for environmental technology information for continual systems analysis, focusing on benefits and risks to ensure that both technologies and R\&D efforts already available are given equal consideration.

\subsection{Environmental Technology Areas}

The categories of Air Force environmental technology requirements based on environmental goals are:

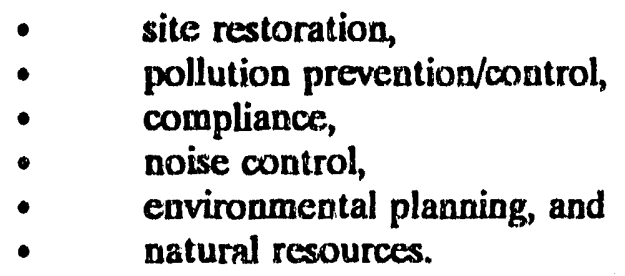

The first two define the technology areas required for environmental operations within the Air Force. The site restoration technologies are similar to those required by other federal agencies. The pollution prevention technologies required by the Air Force and the other DoD services are more nearly unique because of the military base activities and other industrial operations related to maintenance and management of weapon systems. Most of these pollution prevention technologies deal with chemical treatment for eliminating and reducing toxic wastes from operations such as paint stripping, electroplating, degreasing, coating, and rocket propellent disposal. Compliance has technology requirements complementary to those of the first two. Noise control, environmental planning, and natural resources activities have different types of technology requirements; those are being addressed by organizations other than the Air Force.

Air Force requirements for information are similar to those outlined in Sect. 1.4.3. Key types of information it requires are:

- type and applicability of emerging and developmental technologies, 
- environmental technology gaps and R\&D needs,

- assistance in understanding these technologies, and

- real-time response to operational technology information needs in the environmental field.

\subsubsection{Categories of Information}

Under the current Air Force organizational structure, three organizations function as focal points for environmental issues: The Civil Engineer Directorate of Environmental Quality (AF/CEV), consolidates and validates the environmental technology needs of the Air Force; the Air Force Logistics Command (AFLC) is responsible for hazardous waste minimization and industrial processes; and the Systems Engineering Division of AFCESA addresses issues of infrastructure systenis and regulatory compliance.

Environmental technology information requirements are coordinated within the Air Force in the following manner: Requirements for Air Force environmental quality act "vities are directed to AF/CEV. These requirements come from three major subject-specific user focal points: (1) AFCEE for installation programs; (2) AFLC for industrial processes; and (3) AFCESA for infrastructure systems. AFCESA also analyzes requirements, prepares the draft RD\&A Strategic Plan for the AF/CEV, executes the RD\&A program, and provides field solutions. Thus in the Air Force, AFCESA is the most important client for environmental technology information which needs information support in the development of the Air Force Environmental Quality RD\&A Strategic Plan. Asi analytical environmental quality decision support system is necessary to develop alternatives for meeting regulatory requirements after the options available through either procuring or modifying existing technologies or through developing new ones are reviewed. Development of acquisition programs requires information similar to that needed for preparation of RD\&A Strategic Plan.

Like other federal agencies (see Sect. 1.4.3), the Air Force requires near-term and longterm decision support on environmental technology decisions. Requirements in these areas include:

- Near-term decision support (technology information and analysis for logistical operations): Information is needed for site restoration technologies that use biological, chemical, or physical treatment to correct past discharges of previously unregulated chemicals used in Air Force maintenance operations. Site characterization methods and technologies are needed to provide a basic understanding of the contamination problem and identify the technology to resolve it in the most cost-effective manner that meets compliance requirements. Similarly, alternative technologies need to be identified for the disposal of solid rocket propellants (to avoid open burning and detonation) and for reducing hazardous wastes in electroplating, paint stripping, and cleaning in weapon systems maintenance operations. Near-term decision support in these areas is provided by the Environmental Consulting Services Division at Brooks Air Force Base. The EQIAC may support this organization as needed in the assessment and application of emerging technologies.

- Long-term decision support (technology information for program planning, budgeting, and technology acquisition): Most Air Force hazardous wastes are generated by 
operations at Air Logistics Centers. To meet the objective of "reducing hazardous wastes to as near zero as possible," the Air Force needs to identify, develop, and/or track treatment technologies for key industrial operations; reduce use of EPA's 17 priority chemicals; eliminate chlorofluorocarbons and halons; and reduce solid wastes. The planning and acquisition of weapons systems requires an understanding of the technologies needed to comply with the development, acquisition, operational, and maintenance requirements of these new systems. The Air Force needs planning and programmatic information services that would help speed development of technologies required to reach its IRP and pollution prevention goals for the year 2000. Long-term program planning, development, support, and R\&D program development coordination for RD\&A will be the focus of the Air Force EQIAC operations. It will include R\&D planning and forecasting of future environmental technology requirements for new systems and other Air Force operations.

The EQIAC will focus on meeting the long-term decision support needs, since the Air Force has other environmental quality activities, such as AFCEE, focused on meeting near-term field users' needs.

\subsubsection{An Approach to Meeting Technology Information Needs}

Similar to a technology-oriented IAC, the EQIAC, being discussed here for the Air Force, will be dedicated to providing technology-based information in key environmental areas dealing with technologies for environmental compliance, pollution prevention in operations, and new program development in the areas of weapons systems and installation restoration. The purpose of the EQIAC will be to collect, substantiate, analyze, and disseminate scientific and technical information on environmental quality and to provide a focal point for the efficient transfer of environmental technology. The proposed EQIAC would have at least two significant differences from an IAC oriented toward a specific technology: (1) it would cover a broad spectrum of lechnical disciplines as required in the environmental quality technology area; and (2) it would provide real-time, quick response to environmental technology questions.

\subsection{OUTLINE OF MULTI-YEAR PLAN}

This document is organized in several sections, starting with the identification of demand for environmental technology information to meet the organizational and operational requirements.

- Section 1.0 identifies the demand for information and outlines the types of services that the EQIAC would provide; it describes the void in technical support to Air Force environmental decision-makers; and it outlines the requirements for environmental technology information.

- Section 2.0 includes an overview of services and functions of other IACs within DoD and DOE to determine whether the demand for the services outlined in Sect. 1.0 could be satisfied by existing IACs, and to provide lessons learned or background information on the EQIAC. 
- Section 3.0 describes the mission and strategic objectives of the EQIAC.

- Section 4.0 describes the structure of the EQIAC and the services that will be provided. It also outlines the proposed development and evolution of the EQIAC organization and capabilities.

- Section 5.0 describes the information and communication system.

- Section 6.0 describes the proposed EQIAC operational costs and budget.

- Section 7.0 describes the summary and recommendations. 


\section{REVIEW OF COMPARABLE EXISTING IACS}

To learn from existing efforts, avoid duplication, and minimize the learning costs in the development of an IAC, six existing or developing IACs were reviewed. These IACs, all federally supported, were selected because their structure and services are related to the proposed EQIAC. The purpose of the review was to understand the viability of their operations, technical functions, organizational structure, and financing. The IACs reviewed include:

- the Carbon Dioxide Information Analysis Center (CDIAC),

- the Supportability Investment Decision Analysis Center (SIDAC),

- the High Temperature Materials Information Analysis Center (HTMIAC),

- the Metals Information Analysis Center (MIAC),

- the Ceramics Information Analysis Center (CIAC), and

- the Environmental Technical Information System (ETIS).

Although the ETIS is not considered an IAC, it was included because it functions in a related way and it could have a close technical relationship with the EQIAC in the future. Other information networks, such as the Waste Information Network managed by the Hazardous Waste Remedial Actions Program, were also reviewed but not included in this analysis.

\subsection{INFORMATION ANALYSIS CENTER HISTORY}

The IAC concept was a DoD initiative to deal with the explosion of technical information in the post-Sputnik era. The role of the IACs was to:

- track the varied sources of technical information: primary journals, secondary journals, contract reports, letters, trip reports, person-to-person technical correspondence, and proceedings of conferences and workshops;

- analyze the technical information contained in these sources relevant to specific applications areas;

- make the analyzed data available to scientists, engineers, planners, and managers;

- promote awareness of these services to the target user community; and

- take on special studies and analyses to fill gaps in the technical information base.

The purpose was that the cost of funding an IAC operation would be saved manyfold in the increased effectiveness of those who used its output, not only through the use of more accurate and complete technical information, but also through avoiding the cost of unknowingly duplicating work already done by other technologists, especially work that showed that the approach under consideration would not work.

The Defense Advanced Research Projects Agency (DARPA) of DoD was given the responsibility for establishing several DoD IACs. DARPA's first sizable IAC came into being 
at the Willow Run Laboratories of the University of Michigan around 1959 to collate and analyze data on infrared wavelength optical phenomena. This IAC continues to serve the infrared community.

A memorandum of April 19, 1966, from the director of Defense Research and Engineering to the Assistant Secretary of the Army, Research and Development, directed the establishment of eight DoD IACs. Effective July 1, 1971, the funding and administrative responsibility for nine contractor-operated IACs was assigned by the Office of the Under Secretary of Defense for Research and Engineering (OUSDRE) to the Defense Supply Agency, subsequently renamed the Defense Logistics Agency (DLA). Before this move, there had been no centralized management of the IACs.

In 1980, DLA assigned the management responsibility for its nine contractor-operated IACs to the Defense Technical Information Center (DTIC). Currently, there are twenty-three IACs in the DoD. ${ }^{1,2}$ Eleven are administratively managed and funded by DTIC; twelve are managed by other DoD organizations. Within this past year, the DTIC operation, which had received technical guidance from OUSDRE, underwent a change of reporting, and became part of the Defense Business Operations Fund within the acquisition component of DoD rather than the R\&D component. This move is expected to place more emphasis on self support via customer funding than has been the case in the recent past. It is unclear how this transition will affect the DTIC IACs. The non-DTIC IACs are funded by the host service or agency and appear to have good support.

\section{SUMOMARY OF INFORMATION ANALYSIS CENTERS REVIEWED}

Table 2.1 summarizes the characteristics of the IACs reviewed, including the general functions and products of IACs. A detailed description of each of the six IACs is included in Appendix A, along with the elucidation of specific features of each IAC that may be beneficial for consideration in EQIAC development.

Most of the IACs reviewed have been operational and represent the classical IAC. The SIDAC and the ETIS represent the two extremes of the broad spectrum of operational IAC functions: data base maintenance and technical analysis. The SIDAC, when operational, will be dedicated exclusively to acquisition support. It represents an IAC function not emphasized by a standard IAC. The ETIS, on the other hand is purely an information service organization.

The common element of the IACs reviewed was their function as repositories and resources for the latest information in a specific technology field. In addition to collecting, substantiating, and disseminating scientific and technical information in their specific fields, they provide technical analysis and assessments of technology options. In all cases the IACs have three basic functions:

\footnotetext{
1nDirectory of Federally Supported Information Analysis Centers," NTIS Report No. PB-1776050.

2nInformation Analysis Centers in the Department of Defense," DTIC/TR-87/17, AD-184/002, DTIC, Alexandria, VA 22304-6145.
} 
Table 2.1 IAC services

\begin{tabular}{|c|c|c|c|c|c|c|}
\hline & CDIAC & SIDAC & HTMLIAC & MIAC & CLAC & ETIS \\
\hline \multicolumn{7}{|l|}{ FUNCTIONS: } \\
\hline Database Development & $\mathbf{Y}$ & $\mathbf{N}$ & $\mathbf{Y}$ & $\mathbf{Y}$ & $\mathbf{Y}$ & $\mathbf{Y}$ \\
\hline Library Services & $\mathbf{Y}$ & $\mathbf{N}$ & $\mathbf{Y}$ & $\mathbf{Y}$ & $\mathbf{Y}$ & $\mathbf{N}$ \\
\hline Technology/lnformation Transfer & $\mathbf{Y}$ & $\mathbf{N}$ & $\mathbf{Y}$ & $\mathbf{Y}$ & $\mathbf{Y}$ & $\mathbf{Y}$ \\
\hline Technology Assessments & $\mathbf{Y}$ & $\mathrm{X}$ & $\mathbf{Y}$ & $\mathbf{Y}$ & $\mathbf{Y}$ & $\mathbf{N}$ \\
\hline Technical Consultation & $\mathbf{Y}$ & $\mathrm{x}$ & $\mathbf{Y}$ & $\mathbf{Y}$ & $\mathbf{X}$ & $\mathbf{Y}$ \\
\hline Education and Training & $\mathbf{Y}$ & $\mathbf{N}$ & $\mathbf{Y}$ & $\mathbf{Y}$ & $\mathbf{Y}$ & $\mathbf{N}$ \\
\hline Special Studies & $\mathbf{Y}$ & $\mathbf{Y}$ & $\mathbf{Y}$ & $\mathbf{Y}$ & $\mathbf{Y}$ & $\mathbf{N}$ \\
\hline Development of Models and Methods & $\mathbf{Y}$ & $\mathbf{Y}$ & $\mathbf{Y}$ & $\mathbf{Y}$ & $\mathbf{Y}$ & $\underline{N}$ \\
\hline Bulletin Board Service & $\mathbf{Y}$ & $\mathbf{N}$ & $\mathbf{Y}$ & $\mathbf{Y}$ & $\mathbf{Y}$ & $\mathbf{Y}$ \\
\hline \multicolumn{7}{|l|}{ ORGANIZATION: } \\
\hline GOCO & $\mathbf{Y}$ & $\mathbf{N}$ & $\mathbf{N}$ & $\mathbf{N}$ & $\mathbf{N}$ & $\mathbf{N}$ \\
\hline coco & $\mathbf{N}$ & $\mathbf{Y}$ & $\mathbf{Y}$ & $\mathbf{Y}$ & $\mathbf{Y}$ & $\mathbf{Y}$ \\
\hline Government Organization & $\mathbf{N}$ & $\mathbf{N}$ & $\mathbf{N}$ & $\mathbf{N}$ & $\mathbf{N}$ & $\mathbf{N}$ \\
\hline \multicolumn{7}{|l|}{ FINANCING: } \\
\hline Core Funding & $\mathbf{Y}$ & $\mathbf{Y}$ & $\mathbf{Y}$ & $x$ & $\mathbf{Y}$ & $\mathbf{Y}$ \\
\hline User Fees & $\mathbf{N}$ & $\mathbf{N}$ & $\mathbf{N}$ & $\mathbf{N}$ & $\mathbf{N}$ & $\mathbf{Y}$ \\
\hline Multiagency Funding & $\mathbf{N}$ & $\mathbf{N}$ & $\mathbf{N}$ & $\mathbf{N}$ & $\mathbf{N}$ & $\mathbf{Y}$ \\
\hline Independent Task Funding & $\mathbf{Y}$ & $\mathbf{Y}$ & $\mathbf{Y}$ & $\mathbf{Y}$ & $\mathbf{Y}$ & $\mathbf{N}$ \\
\hline Self Supporting & $\mathbf{N}$ & $\mathbf{N}$ & $\mathbf{N}$ & $\mathbf{N}$ & $\mathbf{N}$ & $?$ \\
\hline
\end{tabular}


1. acquisition, verification, maintenance of, and access to technical data;

2. information analysis of technology alternatives and applications; and

3. information and technology transfer.

Most of the IACs reviewed are not full-service organizations. They provide primarily bibliographic information and work in isolation from similar IACs. The least activity is in the area of analyzing information about technology alternatives and applications. SIDAC, when it becomes operational, will provide an important information node in the EQ network by providing analytical decision support of technology alternatives in the acquisition of weapons systems.

A gap exists in current IAC capabilities: There is no full-service, real-time environmental technology information resource. Coordination and a mediator/facilitator among existing IACs is necessary to provide quality assurance for these IACs and promote greater availability of information in the environmental quality community. Federal agencies engaged in environmental compliance have noted the need for a center with access to all available information on environmental technology and with the technical expertise to respond quickly to requests from the field for decision support. No organization within or outside the Air Force provides this service, which is in demand to meet Air Force, DoD, and DOE environmental missions.

\subsection{ISSUES THAT NEED TO BE CONSIDERED FOR IAC DEVELOPMENT}

The review of six existing IACs and the IAC literature highlight several major issues that need to be considered for IAC development.

\subsubsection{Organization}

In all cases, the IACs reviewed are operated by a contractor paid for "core" technical information support, which in some cases is further subcontracted when necessary. Technical support functions are performed by in-house staff. Almost all DoD IACs are contractor operated. The need for contract support for IAC operation can be argued on the basis that the high-caliber technically expert personnel required to accomplish the mission of these IACs are not available in the sponsoring organization. Contractor support also allows the flexibility needed to maintain the mix of technical staff that satisfies the evolving needs of the IAC; government staff cannot be reassigned easily. Additionally, a support contract is for a fixed period of time. Thus the sponsoring organization can change contractors if it finds that its current support contractor is not responsive enough to the growth and change in scope of IAC products and services.

Many of the IACs are operated by universities. For example, three of the six IACs reviewed here are operated by Purdue University, and the ETIS is operated by the University of Illinois. The technical expertise and lower cost offered by universities probably have made them more competitive as contractors for these centers. The IAC funded by DOE (i,e., the CDIAC) is operated by the Oak Ridge National Laboratory, where the technical expertise was developed. 
It is recommended that the IAC initially be small with limited scope, products, and services and that the IAC has enough flexibility to grow as demand for its services grows. It takes time for an IAC to develop its products and clientele. During its initial years of development, many different products and approaches are tested. CDIAC had an unsuccessful experience during its initial years of development, and it was a full five years before CDIAC was able to function on its own. A good strategy is initial development of EQIAC for the Air Force at AFCESA to satisfy a specific Air Force need before it becomes the DoD IAC.

\subsubsection{User Involvement}

Early contact and wolvement by the user community in the evolution of an IAC is critical to ensure its favorable evaluation and fiscal support. IAC staff should strive to find out what its users want and how best the IAC can provide it. The IAC should establish user group communication mechanisms to ensure that its services continue to be relevant. Since electronic communication can be established with other centers in the EQIAC network, electronic bulletin board feedback of user suggestions should be made available to supplement workshops and flyers mailed to promote user awareness.

\subsubsection{Funding}

Establishing an IAC takes time, as it must go through various development phases. Thus the stable funding for core support during the initial years of operation of the EQIAC is critical to its success. A five-year funding cycle for core support is provided so that projects such as handbooks can be undertaken with a good likelihood of successful completion. For example, it was a full five years before CDIAC was able to function on its own; during those initial years it had financial support from DOE. Some of the well-established DOD IACs supplement their operating budgets with income from handbooks of data or bibliographies, but those rarely are a major source of revenue.

\subsection{Procurement}

The procurement method is very important, purticularly if the EQLAC is contractor operated. The procurement methodology should be conducive to features such as quick reaction, responsiveness, and a full spectrum of services. The EQIAC team should include the contracting office as a part of the team, and a mutually-agreed-upon contracting mechanism should be in place that allows for rapid obligation of funding for special studies and tasks, especially those involving subcontractors. An innovative, flexible, and enlightened contracting office is essential to the success of the EQIAr. to provide cooperative contracting support while maintaining the objectivity and accountability necessary to ensure prudent stewardship of public funds. The procurement method currently in use by the contractor"operated SIDAC provides the required flexibility in a funding mechanism.

The request for proposal calls for a three-part award fee with different funding mechanisms. The contract for core services must be for a firm fixed price; the extended services will be costplus-fixed-fee; and the special tasks will be customer funded under a delivery order for each special task. The contractor must be able to perform the core tasks plus a minimum number of the extended services in-house with its own staff. The other extended services and the special tasks may be performed by other firms used as subcontractors to the IAC prime contractor. The 
intent of special tasks is to fill the gaps in modeling identified by the IAC through major modeling development efforts under its cor 2 and extended services.

Satiffying the competition in contracting at the start enables rapid implementation of corrective efforts. The above methodology has historically been used by the DoD LACs. A reexamination of the methodology by DLA and Defense Energy Supply Center that delayed the SIDAC procuremeis: are reportedly resolved, so this key attribute of IACs appears to have current approval.

\subsubsection{Services}

Most IACs have an internal list of experts that they call upon to assist in special studies, but they do not attempt to compile such lists for networking and referral purposes within the community. Such a compilation might be useful for EQIAC.

During the initial years of EQIAC operation, newsletters, workshops, and handbooks will be an excellent means of building visibility in the user community. EQIAC needs to identify and contact members in its user community at the start. Incorporating EQLAC's holdings in some of the existing IACs might allow EOIAC to focus on direct requests for special searches from its users. For example, MIAC and CIAC do not provide a bibliographic reference service directly. Rather, they include their holdings in the Defense Research Development Testing and Evaluation Online System (DROLS) and let all qualified DTIC users gain access by that on-line system. This rninimizes staff, hardware, and software cost but maintains control, visibility, and responsibility.

\subsubsection{Reimbursement of Services}

All DoD IACs are required to recover $50 \%$ of their operating budgets through user charges. The objective of the service charge program is twofold: (1) to encourage each IAC to recover part or all of the costs associated with the output of the IAC in order to provide an income to offset rising costs and (2) to encourage expansion of services to the technical community. Certain services remain free to the user; these vary from IAC to IAC. These might include general information queries, certain kinds of bibliographic searches, or minor technical inquiries.

During EQIAC's initial years, it would be advisable to make its products and services available without charge to authorized users and, when appropriate, to prospective users as a method of building a wider audience than would be likely if a nuisance-level charge were levied. The most likely supplemental revenue source for EQIAC would be special studies and tasks performed in support of DoD and DOE offices, which would pay for them on a case-by-case basis or by an annual support stipend to cover anticipated usage.

\subsection{Communication}

EQIAC will exist in a network of other centers of data and expertise and will permit ease in communication to its users and information sources. A sophisticated communications system 
will be needed to exchange information and data with these diverse users in order to provide fast-turnaround services. The communications network should be a channel of user input regarding the continuing relevance of EQIAC to its client community.

\subsection{Cost-Benefit Value}

All IACs are expensive to operate if only the dollars-and-cents outlay is considered. The broader the IAC's scope, the higher is its operating budget. However, a strong case can be made for the overall cost savings that result from the work of the IAC. The prevention of duplication of effort is cited as one of the major benefits. Not knowing about a piece of relevant information because of an inadequate information transfer process can increase the costs of scientific and technical work. Yet it has not been easy for IACs to quantify their cost-benefit value to the user community. There is no simple way to measure actual savings, and at best only estimates are made. Previous cost-benefit studies have used criteria that arrived at cost savings that were so enormous that they lacked credibility.

A recent study ${ }^{3}$ of selected DoD IACs was performed by the Institute for Defense Analysis to evaluate their contributions to the DoD R\&D program. The study used the "operational audit" approach, similar to the technique used by various auditing agencies of the U.S. government to conduct performance audits. The Nondestructive Testing IAC (NTIAC) used for the pilot study indicated that the benefits to the government exceed NTIAC contract costs by a ratio of at least 3:1. Typical information-related benefits such as objectivity, impartiality, and the authoritative nature of information contributed by the DoD IAC program were emphasized strongly by the users. These remain difficult to quantify.

${ }^{3}$ Forrest Frank and Ed Townsley, "Evaluation of DoD Information Analysis Center Program: Pilot IAC Study," Institute for Defense Analyses, IDA memorandum report M-443, December 1988. 


\section{MISSION AND STRATEGIC OBJECTTVES}

This section outlines the mission and strategic objectives for the developnent of an Air Force EQIAC. The objective reflect the Air Force requirements ovitined in Stet. 1.5, and to some extent, the general requirements outlined in Sect. 1.4. The mission and idevelopmental objectives for EQIACs in other organizations may differ from those of the Air Force.

\subsection{THE EOIAC MISSION}

The mission of the EQIAC is to serve as an authoritative full-senrice center of information, technical expertise, and analysis capabilities in the field of environmetatal quality technology.

The primary exnphasis of the EQLAC is on support to develoners, planners, and decision makers through analysis. These initial capabilities can be supplemenled over a plase-in period with capabilities for information research, assessment, and transfer. The staff of the EOLAC responds to tasks assigned by users and analyzes specified data, producing information of value to those users.

The EQLAC will acquire the necessary technical data and models from network of cooperating information centers and repositories without duplicating the functions or holdings of thuse center and repositories. That acquired information then will be analyzed and the results of these analyses, including the models and tools developed in the process, will become the principal holdings of the EQIAC. The secondary holdings of ECIIAC will be data from the external cooperating network of centers and repositories that the EQIIAC has analyzed and found especially accurate and useful to its mission. Current objectives of the Air Force EQIAC do not include capabilities for yystems analysis support on a daily bissis in the characterization of exiting sites and the environmental cycle of a facility; this service is currently beting provided by other Air Force organizations (see Sect. 4.0). However, systems analysis will be done while providing planning/programmatic support services.

Although the objectives are applicable to all agencies, in the iase: of the Alr Force, the EQIAC will support environmental planning, compliance, and restorution, as wrell as other environmental-quatity-nelated technology thrusts supported by the Air Force Science and Technology Program. The EQIAC resources would serve all Air Fiprci: organizations and the environmenral user community in DoD and other federal agencies. The vision is for the EQLAC to become a focal point and interface between technology information sources and the federal agencies. Figure 3.1 illustrates this technology information "analysiubnoker" conckpt, which is further described in Sect. 4.0.

\subsection{EQIAC SIRATEGIC OBIECTIVES}

Strategic objectives to carry out the mission of EQLAC include the development of resources, capabilities, and operational structure. The strategic objectives of EQLAC are

1. Development of techarical capability. To develop the capability and resources to provide technology-based information, technical analysis and assessment, and 


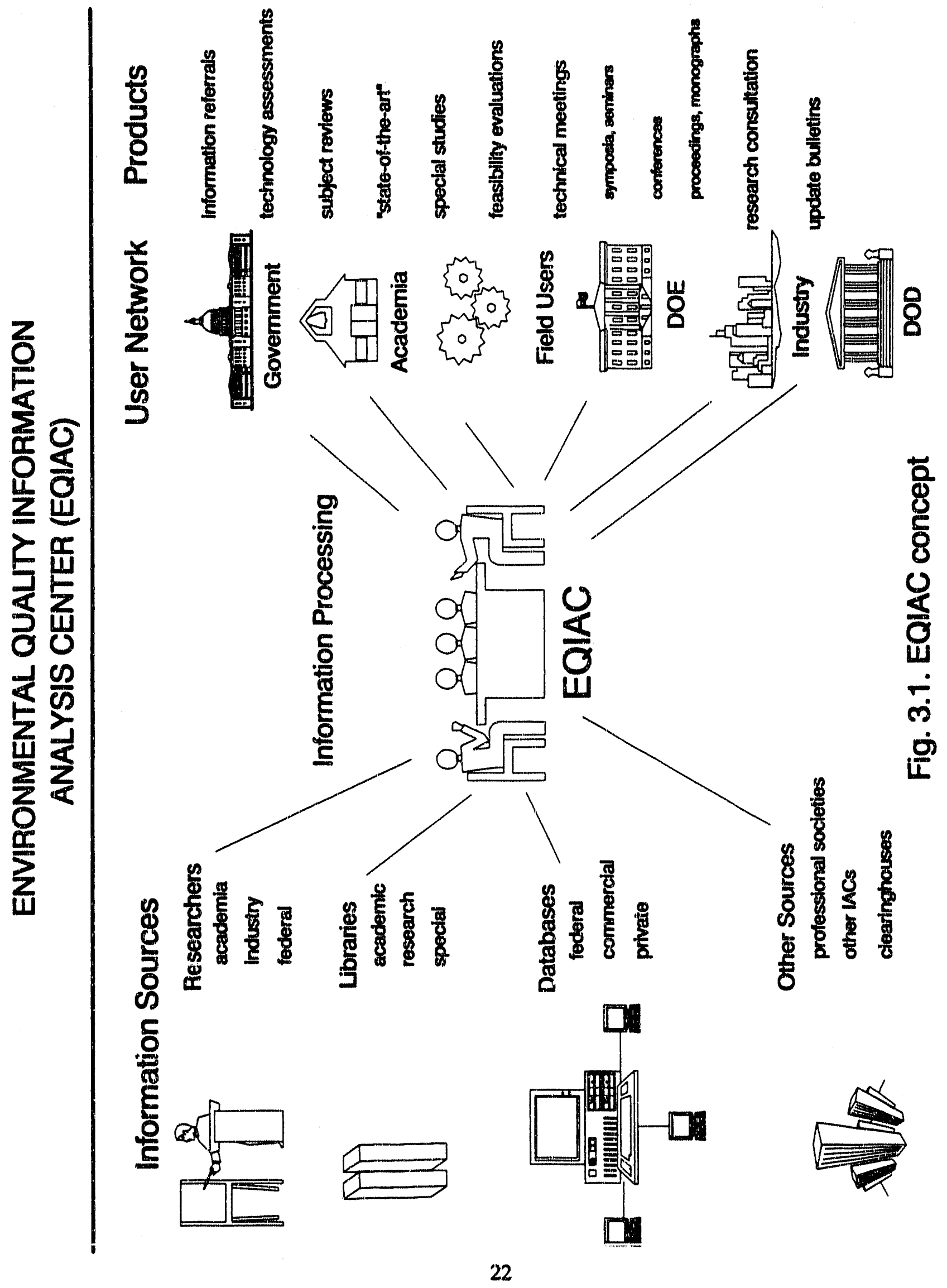


referral and training support to clients in at least two environmental quality thrust areas: (1) site restoration including remedial technologies, and (2) pollution prevention/environmental compliance.

2. Organization development: To develop and maintain a technically preeminent and fiscally viable organization with the ability to respond to demands and challenges effectively with a solid technical and administrative structure.

The following paragraphs provide a detailed description of these two strategic objectives for the development of EQIAC.

\subsubsection{Technical Support Objectives}

The principal technical support objective of the EQIAC is to collect, substantiate, analyze, and disseminate scientific and technical information on environmental quality. A second objective is to maintain and/or access data bases and serve as a collection and dissemination point on environmental technology applications for specific areas such as solid rocket propellant disposal, reduction and elimination of hazardous chemicals and wastes in industrial plant operations, composite waste disposal and recycling, the biodegradation of military wastes, and ozone depletion. A third objective is to be the focal point for the transfer of environmental quality technology to federal environmental and field operations. The EQLAC will provide technology-based information to DoD, DOE, and other clients in key environmental research areas.

Examples of specific activities that would be carried out under these objectives include:

- support AFCEE in its mission of requirements assessment, planning, and restoration support to Air Force organizations;

- $\quad$ support Air Force facility environmental restoration programs and pollution control planning;

- assist the RD\&D community in identifying and forecasting technology development and requirements;

- support DoD, DOE, and EPA in reviewing and coordinating environmental technology R\&D efforts; and

- $\quad$ support other government agencies, academic institutions, and industry on environmental quality concerns.

EQIAC will meet the technical support objectives by providing three classes of services:

1. Scientific and technical services consist of analytical and technological information. Activities may include critical reviews and assessments of new and developing technologies and scientific findings, as well as evaluations of their suitability to particular applications. 
2. Planning and programmatic services consist of analyzing technology requirements, assessing technology, and forecasting. Suggested activities include programmatic assessments, locating off-the-shelf technological alternatives, and developing investment strategies.

3. Technology transfer services include services such as sponsoring and conducting workshops, conferences, and scientific and technical exchanges. This service also would encompass identifying voids in existing data or knowledge bases and helping to fill those voids in an economical, efficient, and unbiased manner.

EQIAC will meet the federal demand for information described in Sect. 1.4 .3 by supplying these services through a matrix as described in the Table 3.1 below.

Table 3.1 Information demand and services supply matrix

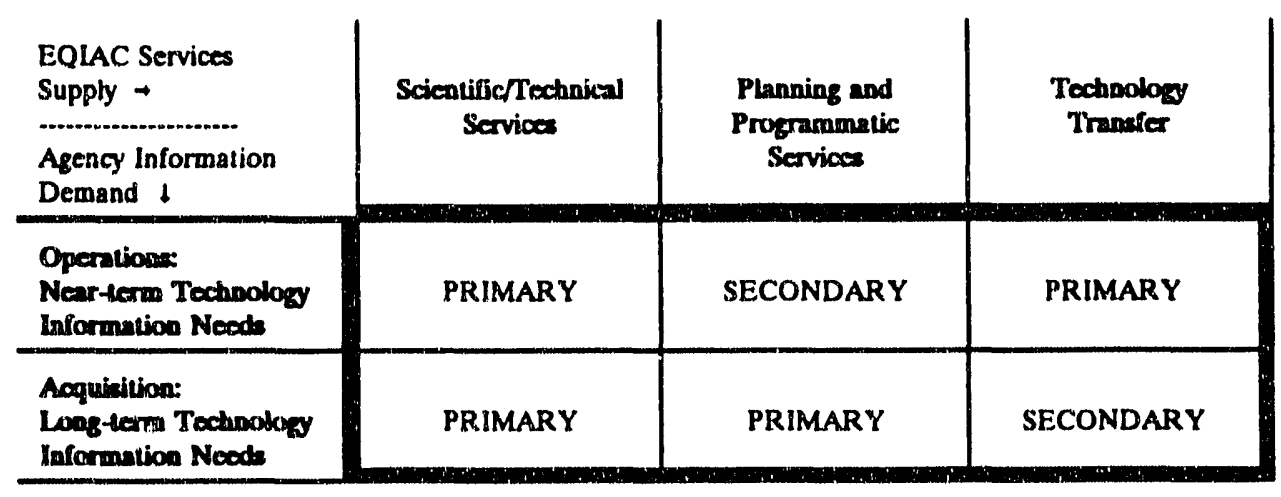

As indicated in Sect. 1.5.3, the Air Force EQIAC will concentrate on providing information on acquisition and less on operations.

\section{2 .2 Organization Objectives}

The success of any organization lies in administrative and management structure. The challenge of EQIAC is to develop a full-service organizational and management structure for the analysis of technological information that is responsive to real-time demand and growth requirements. The following objectives form a structure that will allow EQIAC to grow and respond effectively and efficiently to the operational demands:

- to develop the internal leadership, sub-organization, and staff to carry out the planned analytical support using EQIAC core activities and resources;

- to develop the internal leadership, sub-organization, staff, and systems to collect, generate, verify, and substantiate data on environmental quality;

- to develop and implement an organizational structure, procedures, and an appropriate federal and private network of organizations to carry out effective, rapid information and technology transfer; and 
- to develop and implement an administrative and management structure for program management, financial control, internal program planning and budgeting, staffing, interagency coordination, marketing, and quality control.

The development of an EQIAC organization begins with the implementation of an initial operational capability (IOC) with the necessary resources (i.e., key staff, hardware, and software) to start operations at a viable level. This will allow testing of the concept and structure and facilitate "tuning" of the organizational objectives to aid its development into the full operational capability (FOC). Activities during these stages will include:

- the development of high-quality, preeminent internal staff, including a "blue-ribbon" team of technical consultants to supplement the EQIAC technical capabilities and help to guide the development of the center;

- the development of fiscal stability to maintain EQIAC functions and capabilities through high-quality products and responsiveness to clients, effective business development, realistic and responsive planning and budgeting, and development of corporate clients;

- the development of a self-supporting technology transfer program that includes scheduled conferences, workshops, coordination of technology demonstrations, newsletters, publications, and participation in planning and coordinating functions with other organizations that will make EQIAC the focus of environmental quality technology transfer; and

- the early and effective development of administrative mechanisms that facilitate the participation and use of EQIAC by other federal agencies.

\subsection{EQIAC SCOPE}

In summary, the scope of EQIAC activities will be limited to the development of environmental quality technology expertise to provide scientific and technical information services; technology requirements and assessments for planning, programming, and budgeting; and technology transfer. The key areas to be addressed include site restoration, poliution prevention, and environmental compliance. Technologies include (but are not limited to) bioremediation, physical/chemical remediation, site characterization and monitoring, risk assessment, cost evaluation modeling, reduction of hazardous waste releases, reduced use of EPA priority chemicals, elimination of chlorofluorocarbons and halons, reduced solid waste, reduced greenhouse gas emissions, and compliance with the Clean Air Act and Clean Water Act.

The organization initially will be directed toward internal requirements and marketing for potential users. Services will not be made available to DoD services and federal agencies such as DOE and EPA until FOC is reached. Access to EQIAC services will be paid for through interagency funding transfers. Technical support to other sponsors will be on a case-by-case basis with the condition that these services must not interfere with the primary mission of EQIAC. 


\section{EQIAC DESCRIPTION}

This section outlines a description of the EQIAC as it might be developed within the AFCESA. Consistent with the nodal concept described in Sect. 4.1, this organization would concentrate on very specific areas where there is an immediate need within the Air Force.

EQIAC will operate as an unit within the AFCESA/Research and Acquisition (RA) with funding from AFCESA, other Air Force and DoD services, and DOE. Organizationally, it is ideally placed to provide scientific/technical support services not only to AFCESA but also to other planning units throughout the Air Force. This section of the plan outlines the basic structure of the EQIAC. A detailed description of the organization and procedures is described in the "EQIAC Operating Procedures Handbook," August 1992.

\subsection{ORGANIZATIONAL PHILOSOPHY - NODAL APPROACH}

The demand for environmental technology information services in the federal sector is too large to be met by one organization with limited resources. The number of technology areas and the number of technologies being developed and demonstrated would require a very large organization and many years to develop it. The nodal approach toward developing an EQIAC capability would involve developing environmental technology IACs that concentrate on specific environmental technologies and/or specific technical support services. Some of these nodal organizations would concentrate on providing analytical services and technical analytical support to the field - e.g.,systems analysis, economic impact analysis, and planning support. Other nodal organizations would concentrate on developing capabilities in specific technologies. As indicated, within the Air Force these analysis nodes are operating within other organizations such as AFCEE. These "mini"EQIACs would be coordinated and eventually would form a distributed nodal network. Figure 4.1 illustrates this nodal concept.

For example, an EQIAC node might concentrate on chemical treatment technologies for site restoration and offer technical support capabilities for site characterization and technology applications. Another EQIAC node might concentrate on pollution prevention technologies dealing with DoD industrial and maintenance operations (e.g.,paint stripping, chemical disposal, neutralizing rocket propellent) and offer strategic and program planning support for systems development and technology acquisition. Other EQIAC nodes would offer comparable services in other technology areas. These nodes would be located at facilities that have expertise in specific technology areas: universities, national laboratories, and other federal and private organizations.

\subsection{EQIAC ORGANIZATIONAL STRUCTURE}

Figure 4.2 illustrates the proposed management organization. The program manager will establish the overall goals of EQIAC and provide leadership in the interfaces with the command structure and the interagency coordination. The EQIAC director will manage the distribution of EQIAC resources among the various tasks being processed. Teams will be formed from the personnel of the two principal units, Information Services and Analytical Services, and assigned to the various tasks. A detailed description of the required education, training, and experience 


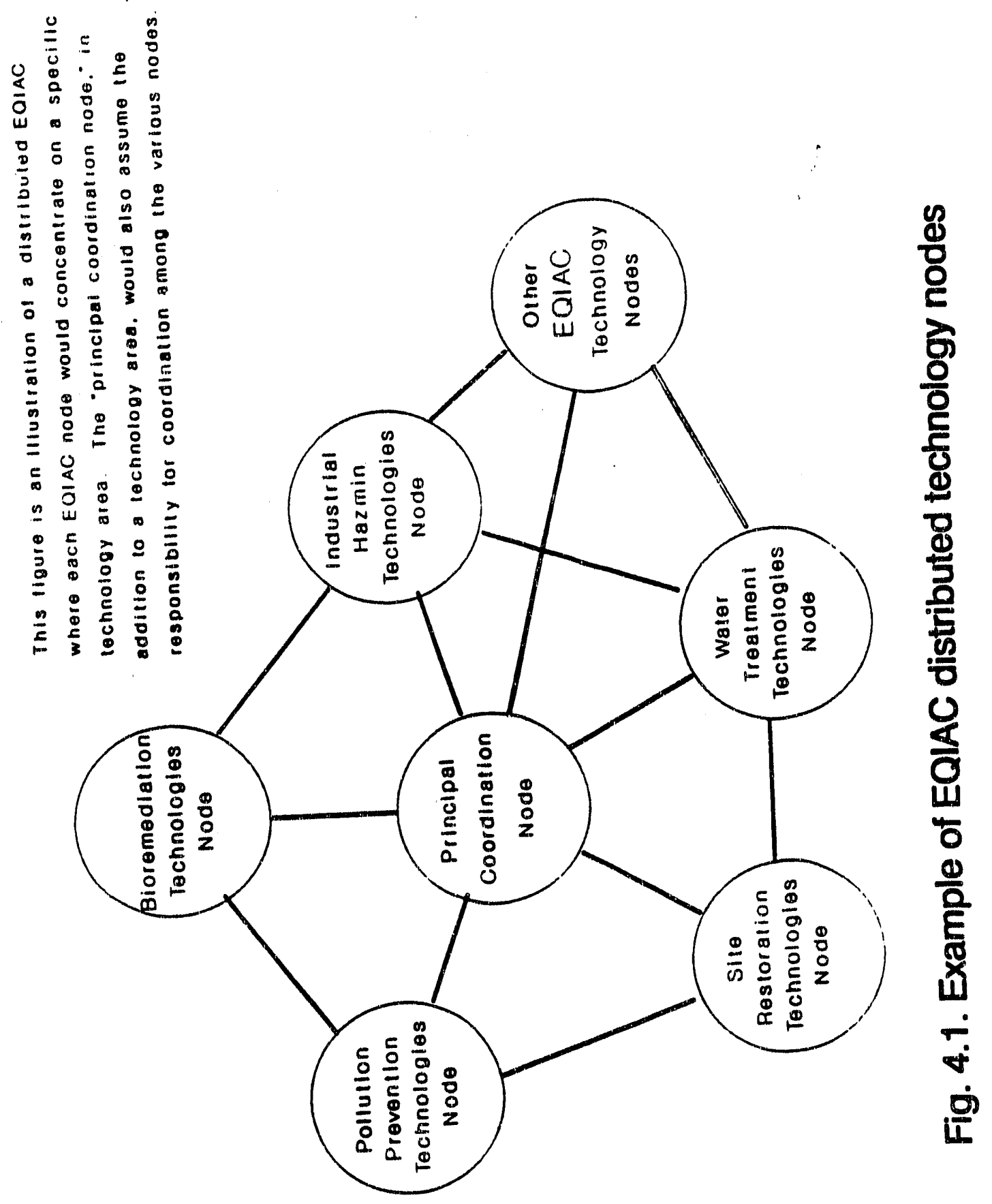




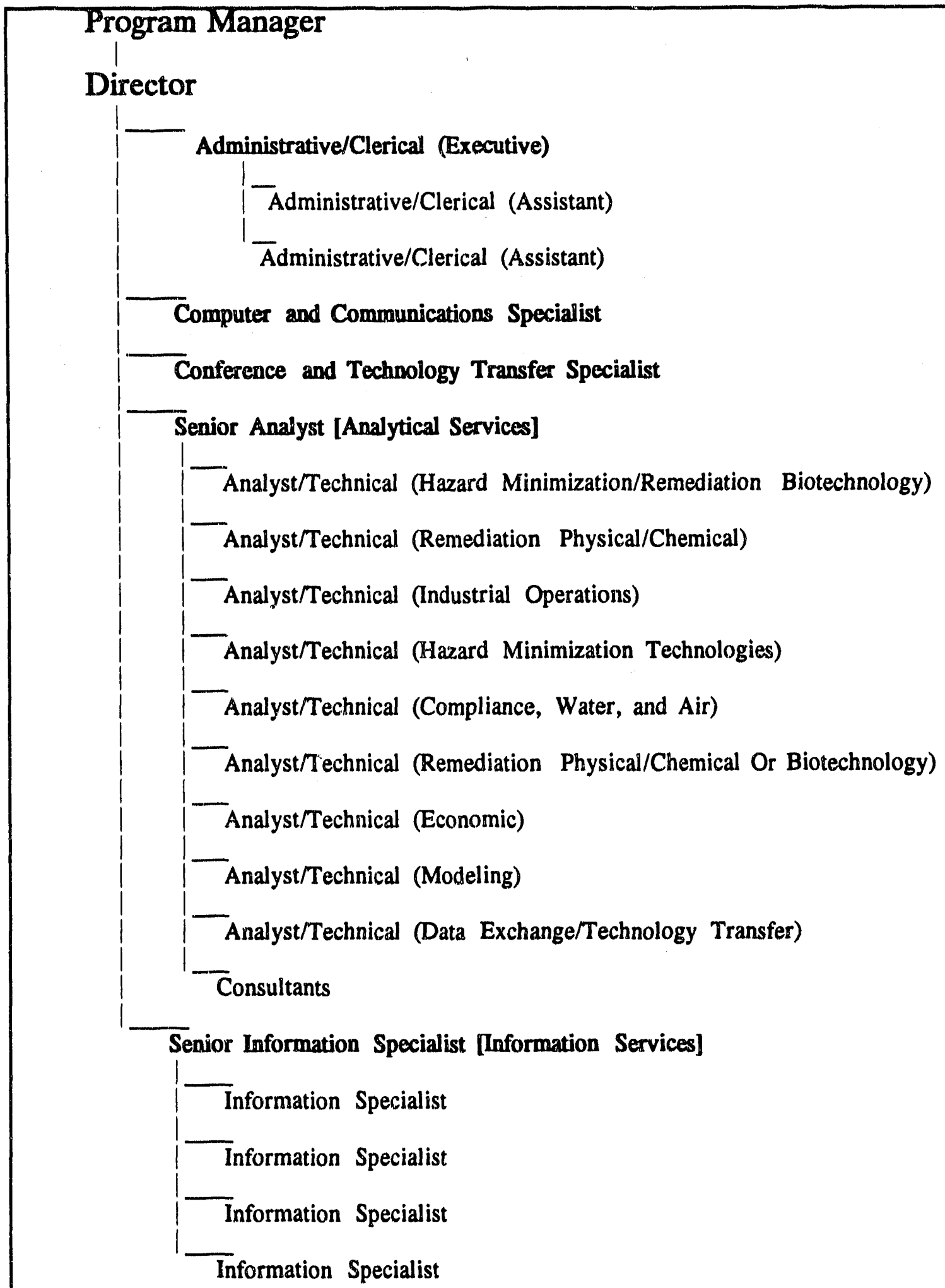

Fig. 4.2 EQIAC organization 
and of the duties and responsibilities for each member of the EQIAC team is provided in the "EQIAC Operating Procedures Handbook."

This section outlines a description of the EQIAC as it might be dev eloped within AFCESA. The leader of the Information Services section, the senior information specialist; and the leader of the Analytical Services section, the senior technical analyst, will be responsible for identifying the members of their staffs that serve on the various task teams; for the professional development of their section; and for advising the EQIAC program director of their future needs for resources. These two sections will work in a matrix management approach to provide the three EQIAC classes of services: scientific/technical, planning/programmatic (including costing/modelling/program evaluation), and technology transfer.

The organization will have technical capabilities in the following areas at a minimum:

- hazardous waste minimization and remediation biotechnologies;

- remediation: physical-chemical and biotechnological;

- industrial operations environmental compliance;

- hazardous waste minimization technologies;

- water and air compliance;

- program technology requirements and alternatives;

- economics;

- $\quad$ system and environmental modeling;

- data exchange and technology transfer initiatives;

- data accession, collection, and distribution;

- bibliographic inquiry responses;

- information verification and comparative analysis;

- $\quad$ support data requirements analysis; and

- abstracts and indexes.

For effective and efficient EQIAC development, three major operational phases are recommended: initial, intermediate, and full. The initial phase will be small enough in scope to establish the concept of EQIAC. The major development of EQIAC will occur during the intermediate operational phase. By the full phase, a full range of services and products is expected to be available. The number of personnel recommended in each of the three development phases will be determined by the products and services to be available to the users during that phase. Sections 4.2.1 through 4.2.3 describe the activities in each of the implementation phases of the EQIAC organization. These activities are summarized in Table 4.1. An aggressive EQIAC development schedule period of 2.5 years is presented in this table; however, reaching stable operation will take around five years. In addition, the exact starting date for each phase will depend on funding availability.

\subsubsection{Phase 1: Initial Operational Capability}

The IOC will be based on resources and personnel drawn from the current military, civilian, and contractor staff at AFCESA. IOC is scheduled for the fourth quarter of 1992. A staff of six will provide services: the director, one administrative/clerical support person, one computer specialist, one information specialist, and two technical analysts. 


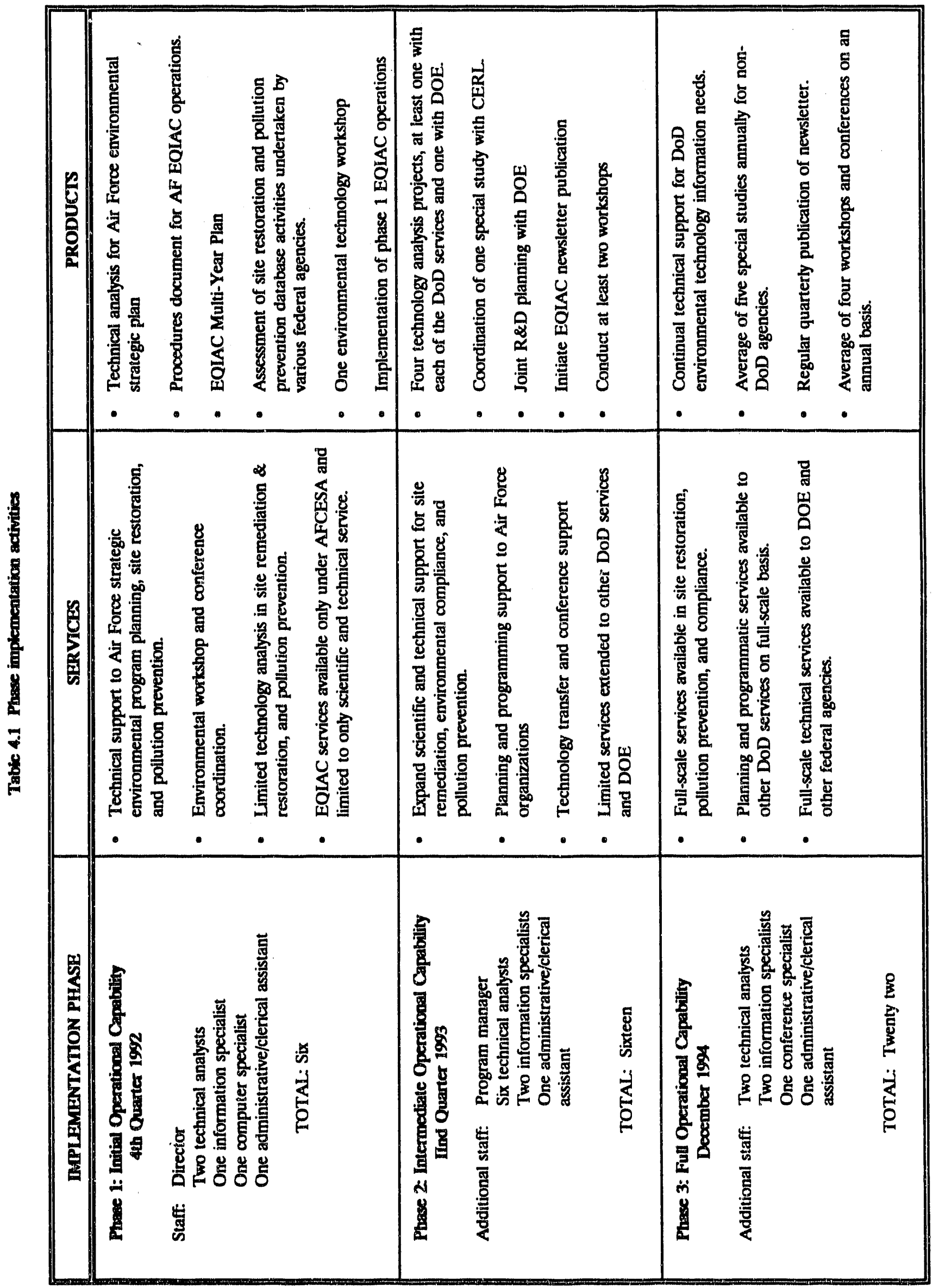


The core group will be connected to a network of cooperating centers to access and share scientific and technical data, computer models, and lessons learned. This initial structure and staff will establish the basic operational interfaces with the other relevant centers in the EQIAC network. Initial EQIAC services will be focused on providing technology analysis support for Air Force environmental quality RD\&A strategic planning activities. Capabilities at this stage will be concentrated in site restoration and remediation technologies. Limited support will be available in technology transfer and routine customer services. One data-exchange workshop should be held with DoD, DOE, and EPA data centers. The initial edition of the EQLAC newsletter should be issued at this stage.

\subsection{Phase 2: Intermediate Operational Capability}

The organization will grow significantly during the second quarter of 1993 by adding staff to reach a total of sixteen. The additional staffing will be accomplished through a support contract. The additional staff will include the EQIAC program manager, one additional administrative/clerical support person, two information specialists, and six technical analysts.

At this stage of development, EQIAC will continue to concentrate on the scientific/technical support for environmental compliance and restoration. Planning and programming support and technology transfer services (conferences, etc.) will be initiated at this stage but will not be promoted until Phase 3. Provision of these two classes of services to other Air Force and DoD elements will begin on a limited basis as appropriate. Scientific/technical and planning/programmatic services will begin to be provided to DOE in targeted projects to lay the groundwork for close interagency coordination via EQIAC. A special study and task should be conducted in conjunction with the U.S. Army Construction Engineers Research Laboratory or an Air Force facility to provide scientific/technical support on an ongoing instailation remediation activity. A special study and task should be conducted to support joint R\&D planning with DOE.

\subsection{Phase 3: Full Operational Capability}

FOC will occur in December 1994 with the addition of two information specialists, two technical analysts, one conference specialist, and one administrative/clerical support person. At this point, planning/programmatic services will be available to other DoD elements, and scientific/technical services and technology/transfer services will be available to DOE and other federal agencies and units. At FOC the core planning/programmatic services of EQIAC will represent approximately 10 to $15 \%$ of EQIAC services. The current awareness newsletter should be published regularly each quarter and an average of five special studies and tasks should be conducted annually for non-DoD agencies. Regular scientific/technical inquiry service should be available through annual retainer funding mechanisms for non-Air Force DoD components. An average of four workshops and conferences should be held annually, one of which should be a users-group annual coordination meeting to plan for future services from EQIAC to its users.

\subsubsection{Specific Recommendations for Phase 1 Development: Air Force Operations}

The initial EQIAC operation should concentrate on activities consistent with the technical support and organizational objectives and commensurate with the resources available. The first phase of development is the most critical in establishing a viable organization. The development of Phases 2 and 3 will have to be based on the success of Phase 1. For this reason, the following initial activities are recommended for Phase 1: 
1. Concentrate on the development of EQIAC capability for site restoration, remediation, and pollution control technologies for the Air Force.

2. Develop or coordinate efficient access to existing information on treatment technologies. This may require compiling an EQIAC technology data base from existing federal data bases.

3. Acquire the services, through initial staffing, contractors/consultants, or appropriate staff, to develop and analyze information in response to technology questions on site restoration.

4. Begin the development of an integrated working relationship with AFCEE and a very close working relationship with DOE/EM.

5. Concentrate on providing technology information and support to the Air Force, and to a limited extent to DOE, on strategic and program planning and budgeting of environmental operations.

6. Develop informational material on EQIAC so that a newsletter on environmental quality technology with full and regular distribution within Air Force and DoD could be initiated at the beginning of the next fiscal year.

7. Accept three to five small technology analysis tasks that can be performed with the initial capabilities of EQIAC.

Although there is a high demand for technology information for all environmental areas (e.g., pollution prevention, environmental compliance, site restoration, and remedial actions), initial efforts in site restoration are recommended for several reasons:

1. Site remediation and restoration for the base closure program will generate a high demand for technical information on the most appropriate and effective approach to preparing Air Force sites for closure and transfer to states and the private sector.

2. Through the AFCEE, EQIAC will have a focused group of clients for site restoration and remediation technologies.

3. Many of the issues and problems encountered within the Air Force in this area are common to the other DoD services and other federal agencies.

Within the site restoration and remediation field, it is recommended that EQIAC concentrate on the following technologies for initial capability development: 


- chemical treatment,
- $\quad$ echlorination,
- $\quad$ in situ bioremediation,
in situ flushing,
- $\quad$ in situ vitrification,
- $\quad$ soil washing,
- $\quad$ thelvent extraction,
- $\quad$ vacuum extraction,

Much research and many demonstrations are being performed in this area, and these technologies could be applicable to many site restoration problems on Air Force bases. Many data bases exist for these technologies, although the consistency, type, quantity, quality, and validity of information may not be the same as is required for EQIAC service. The information available does provide an initial base for developing an EQIAC resource. Analysis and assessment of these existing technology-based data bases are recommended to integrate them into an EQIAC-formatted environmental technology data base.

The success of EQIAC depends on the quality of service, responsiveness, and access to the Air Force market. For this reason, it is important to develop a close partnership with the AFCEE and DOE/EM. AFCEE has direct responsibility for environmental restoration and remediation within the Air Force, and DOE/EM for environmental research and operations within DOE. Growth to critical operating levels of business operations and long-term success for EQIAC will depend on affiliation with these environmental operations organizations.

\subsection{MULTI-AGENCY COORDINATTON}

Coordination within DoD was initiated during the planning phase of EQIAC. Discussions with other information centers and other IACs have generated enthusiasm for establishing cooperative sharing of data, models, analytical techniques, and lessons learned. This close coordination will continue as a regular function of the EQIAC; most of it can be accomplished without additional cost. Coordination with other agencies, particularly DOE and EPA, was also initiated during the original phases of the planning effort. A group of interagency staff have been identified and consulted in the development of this IAC. It is expected that this group of contacts will become regular users of the EQIAC.

The assignment of specific tasks from users within DoD will require transfers of funds to EQIAC. Those transfers can be greatly facilitated by incorporating a method to manage task assignment in the support contract planned for second quarter 1992. The method used by DoD IACs under the supervision of the D'TIC has been to establish a ceiling on the amount for task assignment at contract initiation. As tasks within that established ceiling are considered, two approvals are required before acceptance of a task and funding. First, the technical monitor of the IAC must approve the task as being consistent with the mission of the IAC, supportive of IAC development, and feasible within its current workload. Next, the contracting officer must approve the task as being consistent with the terms and conditions of the primary IAC contract, especially with respect to cost and the performance period. 
To facilitate these technical and contractual reviews, the IAC director will then prepare a proposal to the sponsoring agency that provides sufficient detail for the reviews. If both approvals are received, (and the sponsoring agency approves the proposal content), the contracting officer will modify the primary contract to add the new task. The sponsoring agency then has a specific modification against which it can issue an interdepartmental purchase requisition to transfer the funds, using established finance and accounting procedures.

This approach has been reviewed within the past few years and has been affirmed as appropriate with respect to contractual control and oversight of the procurement process. In the case of the DTIC IACs, the approach functions equally well for tasks from non-DoD federal agencies and is compatible with their interagency financial and accounting procedures. A variant of this procedure within the support contract for the EQIAC personnel would greatly enhance the multi-agency coordination of the EQIAC services.

In this recommended approach for interagency coordination, the decision whether to provide complementary services to other agencies would be made by the program manager, based on the magnitude of the resources needed. For service requests and cooperative interagency projects requiring significant EQIAC resources, the preferred approach would be to propose a modification to the task under the EQIAC support contract to provide the additional resources from the cooperating agency. The proposed approach is described in detail in the "EQLAC Operating Procedures Handbook," August 1992. Other requests would require a proposal prepared by the director and approval from the program manager, the cognizant contracting official, and the cooperating agency.

\subsection{THE FUNDING PLAN FOR EQIAC}

The EQIAC will be funded with both core funding and user charges. Core funding refers to the baseline budget necessary to develop and maintain the capability of the organization and pay for activities not directly related to a specific service. This baseline budget will initially be provided by the Air Force. Later, technical services provided to other branches of DoD and other federal agencies will contribute to a portion of the base-funding requirements.

In addition, EQIAC will provide specific technical analysis beyond its core functions and create and distribute information products on a cost-reimbursement basis. Although much of the technical information services will be free, service charges will be imposed on products and time-consuming services and technical studies. This approach is consistent with DoD requirements that DoD IACs recover $50 \%$ of their operating budgets through user charges.

The objectives of the service charge are: (1) to allow EQIAC a means to recover part of the costs associated with providing a service and (2) to allow for extension of services to the technical community. Charges will be assessed on the basis of costs incurred and according to a pre-established fee structure for specific products and services.

\subsection{REVENUES FROM EQIAC PRODUCTS AND SERVICES}

The reimbursement from EQIAC products and services will represent a source of funding that will be used for core mission functions. EQIAC will develop a system of user charges for the products and services, including a list of charges and users. Reimbursements for IAC 
products and services, exclusive of revenue received from funds provided by federal agencies for special studies and tasks, will be referenced as reimbursements and credited to bills submitted to the government for the products and services provided under the contract.

Revenues received may be in the form of royalties or fees collected for subscriptions or individual products and will be expended within the EQIAC program in a manner that will enhance the technical quality and quantity of products provided. Revenue services may include but are not limited to:

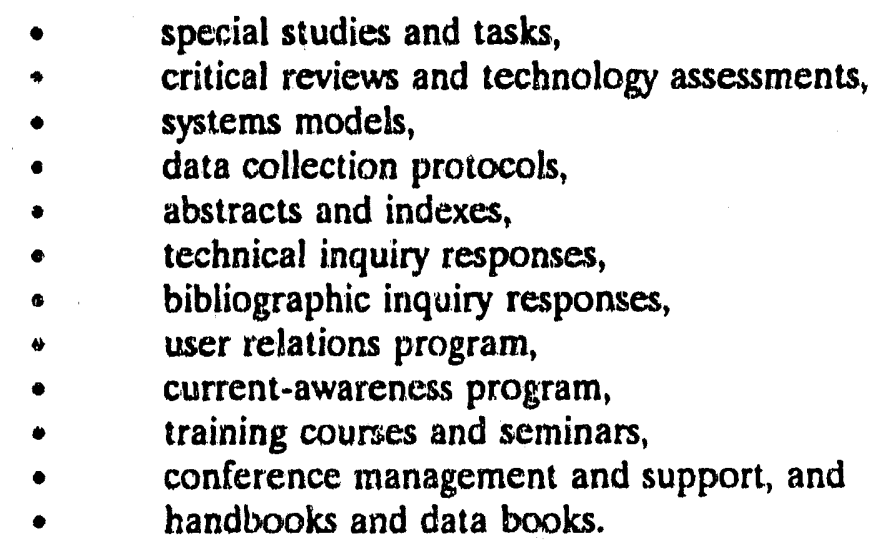




\section{SYSTEM REQUIREMENTS}

This section outlines the system requirements for an operational EQIAC. The procedure for estimating these requirements should be consistent regardless of where the EQIAC exists. However, following the Air Force case example, requirements for an Air Force EQIAC are based on its development in three phases of operational capability.

EQIAC should develop as a stand-alone organization within the AFCESA. There exist resources within AFCESA [i.e., the Technical Information Center (TIC) and computational facilities] ${ }^{4}$ that will be useful during the periods of its IOC and the transition to FOC. The EQIAC telecommunications network will operate as an independent network within AFCESA, communicating with TIC resources similar to other IACs.

The EQIAC telecommunications network needs to satisfy several functional capabilities. As discussed earlier, EQIAC will not be limited to using conventional sources of information (e.g., bibliographic, on-line data bases) to satisfy its diversified user needs. Existing IACs that are already assisting the Defense Research, Development, Demonstration, Testing and Evaluation scientific and engineering personnel through the timely dissemination of evaluated information in their fields of specialization provide an excellent source for EQIAC to satisfy DoD's and DOE's technology-based information needs in key environmental technology areas. Most of these IACs and on-line data bases can be accessed by direct dial-ups through modems. In addition, some of these IACs can be accessed through wide area networks (WANs). The WAN connection (e.g., Defense Data Network (DDN) and Internet) to the local area network (LAN) facilitates improved communication for the information specialists and the technical analysts with DoD and other federal LACs and for EQIAC users worldwide. The Internet connection, for example, will facilitate improved sharing of information from DOE, because the Energy Sciences Network (ESnet) (connected to several supercomputers) of its Office of Energy Research is connected to the Internet. In the future, it is expected that all federal agencies involved in remediation activities will be connected to the Internet to facilitate information exchange.

It is assumed that only information specialists will be accessing IACs and on-line data bases. These IACs will provide a network of technology transfer nodes to facilitate information access by and to industry. These technology transfer nodes will be the agents between EQIAC and the private sector and provide all the services to private clients that EQIAC provides to federal clients on a cost-reimbursement basis. EQIAC also will access currently available data bases and models frequently. Since EQIAC is not intended to be a repository for models, capability should exist for easy electronic data transfer for analysis to sites where the models reside.

\footnotetext{
TIC has an extensive collection of more than 36,000 volumes of periodicals, 110,000 technical reports, 150,000 military and commercial standards and specifications, and 535 periodical subscriptions. In addition, TIC has on-line access to ower 1,000 databases and manages technology information for sonic boom research, privatization, hazardous waste minimization, and rapid runway repair. Computing facilities at AFCESA include (1) three Wang VS minicomputers (\$eries 5000, 7000, and 8000) and a CDC Cyber computer (series 830); (2.) four Defense Data Network (DDN) connections to each of these four computers via the Air Force concentrator; and (3) a local area network limited within the computer room. These rescurces are shared among other Air Force installations and federal agencies mostly by means of dial-up modeins.
} 
Ease of network expansion and interoperability are the most important considerations in the selection of specific hardware and software for EQIAC telecommunication requirements. Networking needs will increase with the growth of demand for EQIAC products and services. For example, in addition to more terminals, modem connections, and computational power, the IACs with a higher usage rate should have access capability through WANs. Interoperability will be the major consideration for EQIAC, as numerous and different computer networks will be involved. There will be several LACs and on-line data bases that need to communicate either by WANs or by direct dial-up through modems. EQIAC's communication capabilities will influence its services. However, user access to EQIAC will be limited to its products and services; users will not have direct access to its data bases and archives.

\subsection{SYSTEM DESCRIPTION}

Figure 5.1 shows the proposed communication network for EQIAC in the projected FOC mode. Hardware and software requirements for each phase of operation are indicated in Table 5.1. Estimates for these requirements are based on the nature of EQIAC products and services to be provided during each of the three phases discussed earlier. The communications network description concentrates more on functional aspects of the network than on specific hardware/software information. A LAN is essential for EQIAC to be responsive and have a quick turnaround. The number of peripheral devices to be connected to the LAN may well be governed by the availability of funds and the extent of services to be provided by EQIAC during a particular phase. The following paragraphs suggest how FOC of the EQIAC communications network will be achieved during its three operational phases.

\subsubsection{Phase 1 (Initial Operational Capability)}

The main aim during Phase 1 of EQIAC is to set up the basic LAN so that additions can be made during its subsequent two phases to develop full operational capability. A LAN with a hardware platform containing the on-line bibliographic software (i.e., BASIS/TECHLIB+), a modem server and modem stack, personal computer (PC) terminals and workstations are suggested during this phase. The BASIS/TECHLIB + software will give EQIAC the capability to catalogue its holdings, products, and services. The EQIAC LAN also can be connected to the existing LAN in the computer room at AFCESA in the future, if necessary. The EQIAC LAN will allow sharing of peripheral devices such as printers among EQIAC team members. Communication outside EQIAC (i.e., on-line databases, LACs, and AFCESA resources) and with EQIAC users will be through dial-up modems. Workstations are suggested for technical analysts and information specialists and PC terminals for the program manager, director, and clerical assistants. The hardware plattorm will serve multiple purposes, including use as electronic mail and ethernet servers and file servers for PC terminals and workstations. The use of the hardware platform as a file server will optimize the memory and storage requirements of each PC terminal and workstation.

Purchase of the site license for the basic software (e.g., word processor, spreadsheet, and data base manager) is suggested during this phase to eliminate purchases in subsequent phases when more PC terminals and workstations will be added to the LAN. 


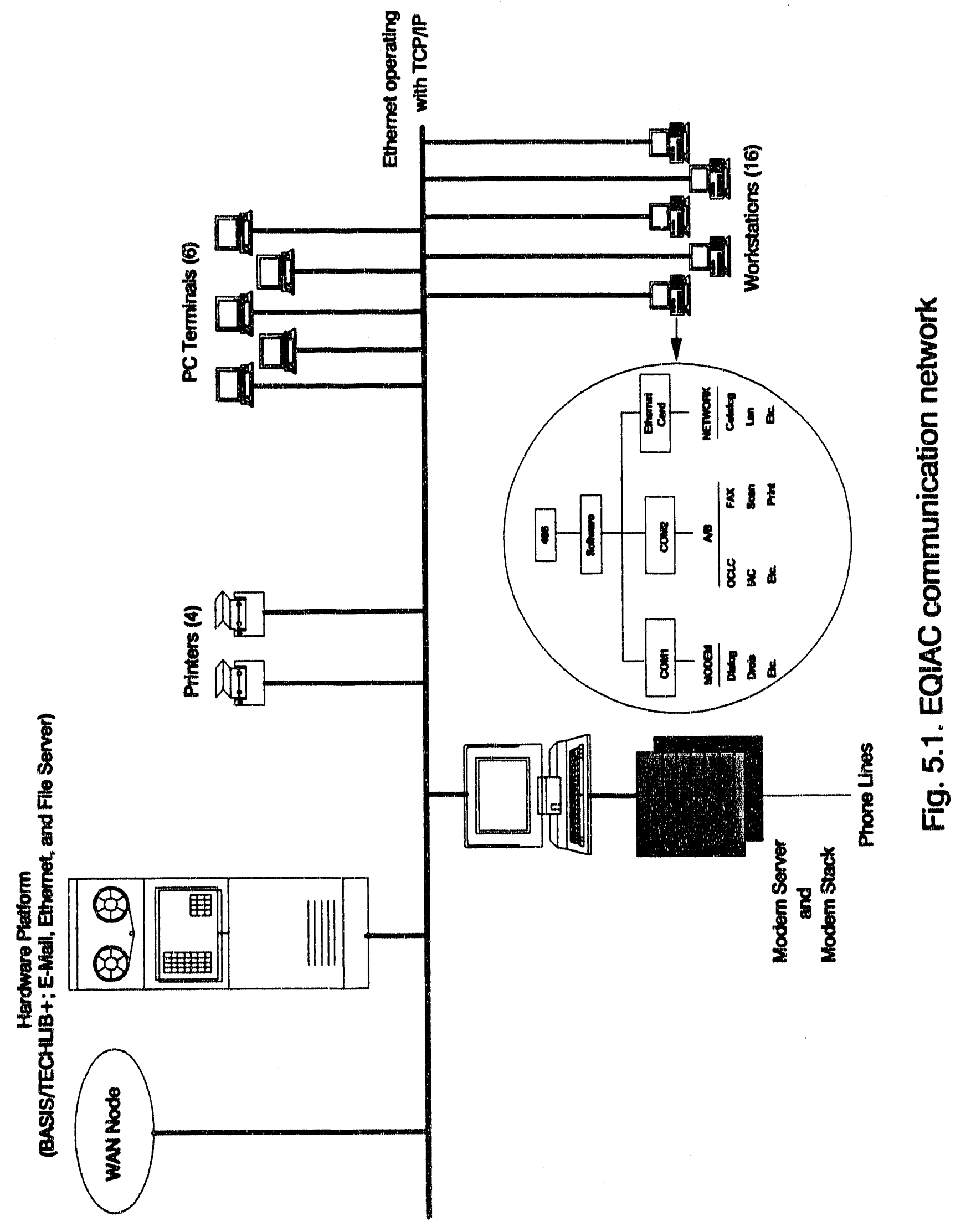


Table 5.1 EQIAC system requirements

\begin{tabular}{|c|c|c|c|}
\hline Phase & $\begin{array}{l}\text { Prunctionsal } \\
\text { Requirements }\end{array}$ & Handware & Software \\
\hline 1 & $\begin{array}{l}\text { Establish the basic EQLAC } \\
\text { communication network by providing } \\
\text { a Local Area Network which in } \\
\text { subsequent phases could be enhanced } \\
\text { to provide the FOC capability of } \\
\text { EQIAC. }\end{array}$ & $\begin{array}{l}\text { a. Loral Area Network (ethernet with } \\
\text { TCPAP protocol); } \\
\text { b. A hardware platform with at least } \\
128 M B \text { RAM for ethernet, e-mail, } \\
\text { and file server; } \\
\text { c. A modem server and modem stack; } \\
\text { d. Two PC terminals and four } \\
\text { workstations; } \\
\text { e. A printer and a facsimile machine; } \\
\text { and } \\
\text { f. Two combination facsimile } \\
\text { machines. }\end{array}$ & $\begin{array}{l}\text { a. Site license for basic software } \\
\text { (word processor, spreadsheet, } \\
\text { and database manager); } \\
\text { b. Communication software for } \\
\text { two PC terminals and four } \\
\text { workstations; } \\
\text { c. Application software for four } \\
\text { workstations; and } \\
\text { d. BASIS/TECHLIB + : On-line } \\
\text { bibliographic software }\end{array}$ \\
\hline 2 & $\begin{array}{l}\text { Additional hardware and software } \\
\text { requirements to meet the needs of } \\
\text { new EQLAC staff (EQIAC team } \\
\text { members increase from } 6 \text { to 16). }\end{array}$ & $\begin{array}{l}\text { a. Two PC terminals and eight } \\
\text { workstations; } \\
\text { b. Two printers and a facsimile } \\
\text { machine; snd } \\
\text { c. Four combination facsimile } \\
\text { machines. }\end{array}$ & $\begin{array}{l}\text { a. Communication software for } \\
\text { two PC rerminals and eight } \\
\text { workstations; and } \\
\text { b. Application software for eight } \\
\text { workstations }\end{array}$ \\
\hline 3 & $\begin{array}{l}\text { Upgrade the memory of hardware } \\
\text { plattorm to } 256 \mathrm{MB} \text { and connect } \\
\text { Wide Area Network (i.e., DDN) to } \\
\text { the ethernet in order to support } 22 \\
\text { EQLAC team memhers and provide } \\
\text { full EQLAC products and services. }\end{array}$ & $\begin{array}{l}\text { a. Memory upgrade of hardware } \\
\text { platform to } 256 \mathrm{MB} \text {; } \\
\text { b. Two PC terminals and four } \\
\text { workstations ( Two - 4MB RAM; } \\
\text { Two - 32MB RAM); and } \\
\text { c. Four combination facsimile } \\
\text { machines. }\end{array}$ & $\begin{array}{l}\text { a. Communication woftware for } \\
\text { two PC terminats and four } \\
\text { workstations; and } \\
\text { b. Application software for four } \\
\text { workstations }\end{array}$ \\
\hline
\end{tabular}

\subsubsection{Hardware}

For Phase 1, a LAN connecting to a hardware platform, a modem server and modem stack, two PC terminals (for the director and an administrative/clerical assistant) and four workstations (for two technical analysts, an information specialist, and the communication specialist) are suggested. Ethernet with a backbone topology is suggested for the LAN, using TCP/IP as the protocol. The TCP/IP will offer the handling capability for data communication between multivendor systems over a variety of networks, including $802.3 \mathrm{LANs}$. The TCP/IP must be the full package, including File Transfer Protocol, TELNET (terminal connection protocol), and Simple Mail Transfer Protocol. TELNET will offer remote terminal log-on services between systems running TCP/IP.

It is suggested that the hardware platform be a separate dedicated minicomputer (RISCbased UNIX processors) with an initial memory of at least $128 \mathrm{MB}$, expandable to 256MB RAM during the FOC. At least $4 \mathrm{MB}$ of RAM is required per user of BASIS/TECHLIB+. The hardware platform will serve ethernet and e-mail servers as well as file servers for PC terminals and workstations. Each workstation will be a 80486-based PC with at least $4 \mathrm{MB}$ of memory; a 40MB hard disk; dual-disk drives; an ethernet card; a computer-driven combination facsimile machine, scanner, and printer to send and receive documents directly (e.g., Canon FAX-225); 
a dot-matrix printer, a laser printer available through the network; two serial ports; and one parallel port. There will be four phone line connections to each of these workstations: (1) a dedicated line to On-line Computer Library Center for Interlibrary Loan service; (2) a line for a modem to access on-line databases, IACs, and full-text information vendors; (3) a line used by the facsimile machine; and (4) a telephone line. The combination facsimile machine will scan documents into computer memory either as a facsimile image, or, using optical character recognition, as ASCII files. These machines are suggested for all information specialists but not for all technical analysts. In this phase, two of these machines are suggested, one for the information specialist and the remaining one to be shared by two technical analysts.

Each PC terminal will be a 80486-based PC with 640K of memory; dual-disk drives; an ethernet card; a dot-matrix printer, a laser printer available through the network; one serial port; and one parallel port. The modem server and modem stack with several phone lines indicated on the ethernet provide dial-up access for EQIAC users to its products and services and for information specialists to on-line searches and communication with other IACs. In addition, one printer connected to the LAN and one facsimile machine for the director's office are necessary.

\subsubsection{Software}

All basic software will reside on the hardware platform and be shared by users connected to the LAN. The basic software will include a word processor, a spreadsheet, and a data base manager. Technical analysts and information specialists will require additional application software to satisfy their specific needs. All PC terminals and workstations will require communication software to communicate with the LAN. The on-line bibliographic software, BASIS/TECHLIB +, is the other major software required during this phase.

\subsubsection{Phase 2 (Intermediate Operational Capability)}

The intermediate phase will add ten staff members to the existing six EQIAC team members. Major improvements to the communication network will include adding eight workstations and two PC terminals to the LAN for the new EQIAC team members.

\subsubsection{Hardware}

Main hardware requirements during Phase 2 of EQIAC are eight workstations and two PC terminals. In addition, four combination facsimile machines (one each for two information specialists, the remaining two to be shared among six technical analysts), two printers connected to the LAN, and one facsimile machine for the program manager's office is necessary.

\subsubsection{Software}

Software requirements in this phase include communication software for workstations and PC terminals and application software for eight workstations. 


\subsubsection{Pbase 3 (Full Operational Capability)}

Six more team members will be added for a total of 22 during the final implementation phase. Connecting the LAN to the WAN (e.g., initially DDN and Internet) and expanding the memory of the hardware platform from $128 \mathrm{MB}$ to $256 \mathrm{MB}$ are suggested, as all EQIAC products and services are expected to be available during this phase. Connecting to DDN and Internet will facilitate improved communication for the information specialists and the technical analysts with DoD and other federal LACs and facilitate communication for EQIAC users worldwide. Two analysts will be involved in cost modeling and economic analysis. To meet their extensive analytical requirements, two workstations with a memory of at least 32MB are suggested.

\subsubsection{Hardware}

Hardware requirements in this phase include (1) connecting the WAN to the LAN; (2) adding four workstations (two with 32MB RAM and other two with 4MB RAM); (3) expanding the memory of the hardware platform to $256 \mathrm{MB}$; and (4) increasing the number of concurrent users of the hardware platform from six to sixteen. Memory expansion of the hardware platform is suggested to meet the full demand for EQLAC services expected to begin during this phase. In addition, two PC terminals, four combination facsimile machines (one each for the two information specialists and two technical analysts) and one printer connected to the LAN are necessary.

\subsubsection{Software}

Software requirements in this phase include communication software for workstations and PC terminals and application software for four workstations. 


\section{PROJECTED EQIAC COSTS}

This section outlines the costs of implementing and operating the EQIAC. It includes a breakdown of the labor and nonlabor components of operation costs. It assumes the EQIAC will operate at Tyndall Air Force Base, Florida, and will be operated initially by government staff with consultant support and later by a contractor.

\subsection{COSTS OF EQIAC OPERATION}

Several assumptions have been made in estimating the cost of EQIAC operation. These assumptions are based on the staffing profile outlined in Sect. 4.0 and the system requirements outlined in Sect. 5.0.

The labor costs for Phase 1 assume current AFCESA personnel. Staff for Phase 2 and Phase 3, except the program manager, will be contractor personnel. Figure 6.1 and Table 6.1 summarize the total cost of EQIAC operations through FY 1994. The following subsections discuss in detail labor and nonlabor cost components of the total cost.

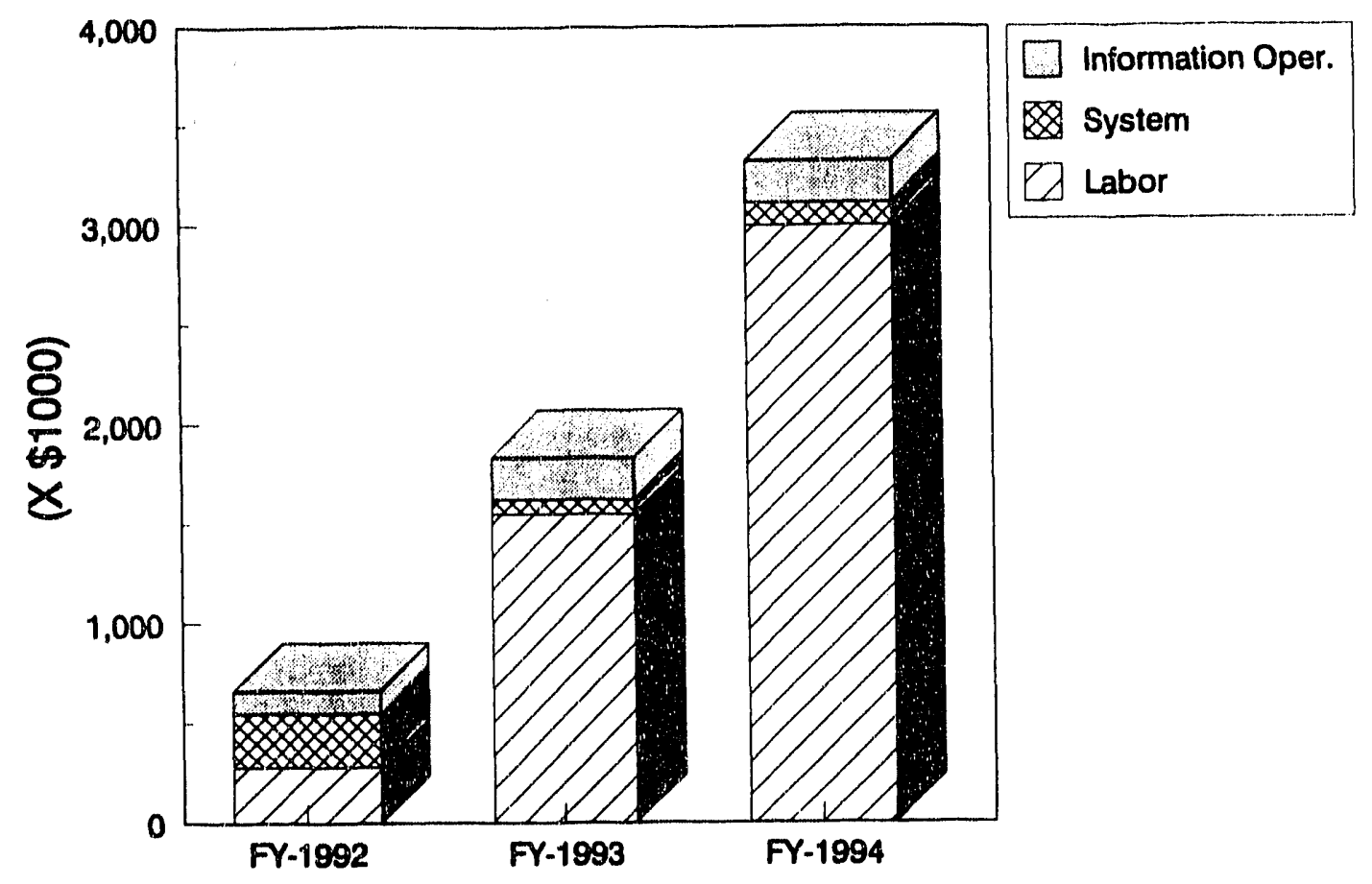

\subsubsection{Labor Costs}

Fig. 6.1. Projected EQIAC operations cost

Table 6.2 outlines the labor cost projections for EQIAC consistent with the labor categories described in Sect. 4.2. The table lists the percentage of time for the fiscal year, the base salary for each staff category, and the full burdened cost per year. A $5 \%$ salary escalation is assumed for the second and third years. 


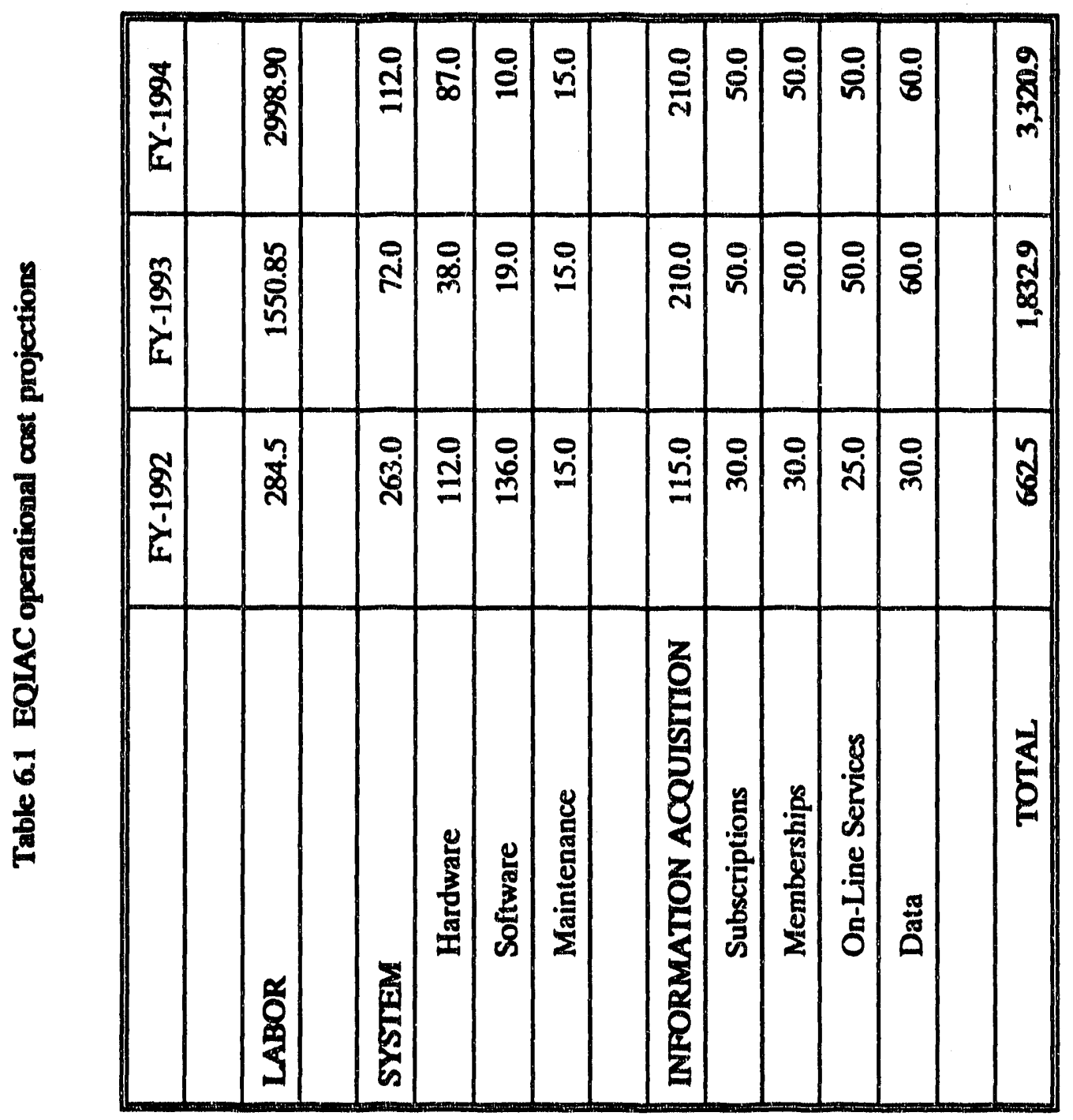




\begin{tabular}{|c|c|c|c|c|c|c|c|c|c|c|c|c|c|c|c|c|c|c|c|c|c|c|c|c|}
\hline & 勇 & 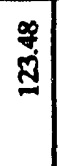 & 㺃 & $\stackrel{5}{5}$ & స్ & $\stackrel{\infty}{F}$ & ซี & 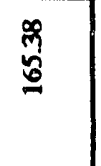 & 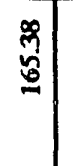 & 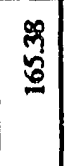 & 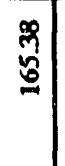 & 竎 & $\begin{array}{l}0 \\
\vdots \\
0\end{array}$ & $\begin{array}{l}\stackrel{0}{0} \\
\hat{6}\end{array}$ & $\begin{array}{l}\mathscr{\tilde { V }} \\
\underline{6}\end{array}$ & 条 & జ్లి & $\stackrel{\infty}{\stackrel{2}{F}}$ & శ్రి & 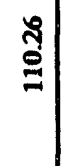 & 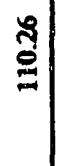 & $\stackrel{\$}{\Xi}$ & తి & 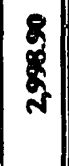 \\
\hline$\frac{\pi}{5}$ & 舆 & $\frac{7}{6}$ & ڤ્ळ & $\stackrel{\overrightarrow{2}}{\not{\sigma}}$ & $\stackrel{8}{\stackrel{8}{*}}$ & ڤે & $\stackrel{8}{:}$ & : & : & )్రి & : & 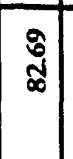 & : & : & $\begin{array}{l}\text { : } \\
\text { త్ర }\end{array}$ & హ్ & $\frac{n}{8}$ & ڤ్ & $\stackrel{m}{\vec{n}}$ & $\frac{m}{\sim}$ & $\stackrel{m}{n}$ & $\stackrel{m}{n}$ & $\stackrel{m}{\bar{n}}$ & ह \\
\hline & * & $\stackrel{-}{-}$ & $\stackrel{\circ}{-}$ & $\stackrel{-}{-}$ & $\stackrel{-}{-}$ & $\stackrel{-}{-}$ & $\stackrel{.}{-}$ & $\stackrel{9}{9}$ & $\stackrel{\circ}{-}$ & ? & 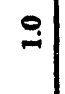 & $\stackrel{9}{-}$ & 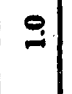 & $\stackrel{\circ}{-}$ & $\stackrel{-}{-}$ & $\stackrel{9}{-}$ & $\stackrel{9}{-}$ & $\stackrel{ }{-}$ & $\stackrel{\circ}{-}$ & $\stackrel{\circ}{-}$ & 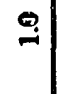 & $\stackrel{\circ}{-}$ & $\stackrel{ }{-}$ & มี \\
\hline \multirow{3}{*}{ 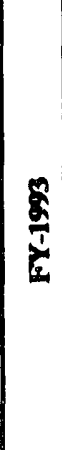 } & 㬓 & 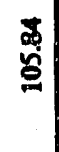 & $\stackrel{n}{\frac{n}{ \pm}}$ & $\stackrel{0}{8}$ & 吕 & 高 & 竎 & $\underset{\infty}{n}$ & $\underset{\infty}{\approx}$ & $\underset{\infty}{\infty}$ & $\underset{\infty}{n}$ & $\stackrel{n}{\square}$ & 8 & $\begin{array}{l}8 \\
8 \\
6\end{array}$ & 8 & 8 & 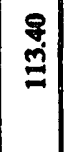 & 8 & $\underset{ }{8}$ & में & पू & 8 & $\frac{8}{2}$ & 番 \\
\hline & 卷 & $\begin{array}{l}\mathbb{8} \\
\stackrel{\infty}{n}\end{array}$ & $\underset{\infty}{\stackrel{n}{\infty}}$ & శ్రి & 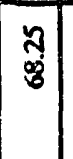 & $\frac{2}{2}$ & స్ & 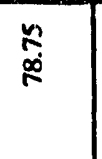 & $\begin{array}{l}n \\
\infty \\
\infty\end{array}$ & $\underset{\infty}{\stackrel{\sim}{\infty}}$ & $\underset{\infty}{\stackrel{n}{\infty}}$ & $\underset{\infty}{\stackrel{n}{\infty}}$ & $\underset{\infty}{\infty}$ & 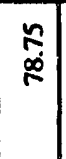 & $\underset{\infty}{\check{\infty}}$ & $\begin{array}{c}n \\
\infty \\
\infty \\
\infty\end{array}$ & 胥 & $\underset{\sim}{n}$ & 8 & $\begin{array}{l}8 \\
: \\
:\end{array}$ & $\begin{array}{l}\text { \&ి } \\
\text { ڤ్ }\end{array}$ & స్ & Б్ & 8 \\
\hline & 空 & 8 & 9 & 9 & 8 & ก & gे & y & $y$ & $\tilde{y}$ & $\check{0}$ & $g$ & : & $\ddot{0}$ & 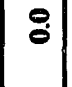 & $\stackrel{8}{\circ}$ & 9 & 8 & : & $\stackrel{9}{-}$ & $\stackrel{乛}{-}$ & : & 8 & $\boldsymbol{N}$ \\
\hline \multirow{3}{*}{$\frac{2}{2}$} & 兽 & $\begin{array}{l}8 \\
\varnothing \\
\varnothing\end{array}$ & 8 & $\frac{\sigma}{2}$ & శ్ & 8 & శ్ & 8 & 8 & 8 & 8 & 8 & \&్ర్ర & 8 & 8 & 8 & \begin{tabular}{l}
$\mathbb{8}$ \\
\hdashline \\
$\mathbf{9}$
\end{tabular} & 8 & 8 & 8 & 8 & 8 & $\begin{array}{l}8 \\
\dot{m}\end{array}$ & ฟิ \\
\hline & 量 & 审 & 웃 & $\stackrel{7}{j}$ & :̊. & 离 & : & ํㅗ & $\dot{i}$ & 옴 & 요 & i. & 웅 & 옴 & غ્) & $\ddot{\text { : }}$ & 8. & : & 을 & हें & 욜 & : & : & $\begin{array}{l}8 \\
8 \\
8 \\
2\end{array}$ \\
\hline & R E & 9. & 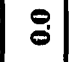 & : & $\ddot{0}$ & $\stackrel{8}{\circ}$ & \& & 8 & $\stackrel{0}{0}$ & $\because$ & $\because$ & 8 & $\stackrel{\circ}{\circ}$ & $\stackrel{8}{\circ}$ & 8 & $\stackrel{\circ}{\circ}$ & $\ddot{0}$ & $\stackrel{8}{0}$ & 8 & $\stackrel{8}{\circ}$ & : & 8 & : & 욤 \\
\hline & 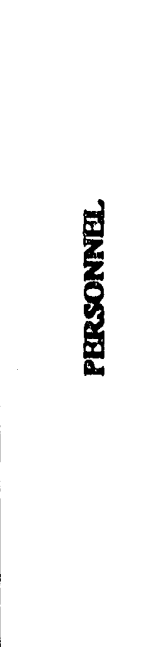 & 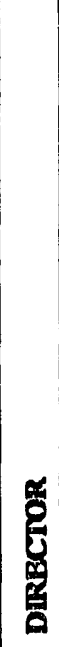 & 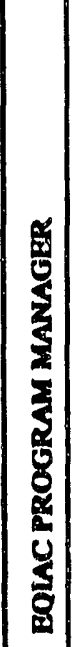 & 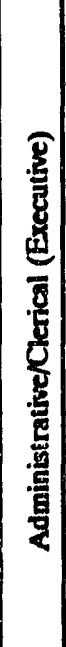 & 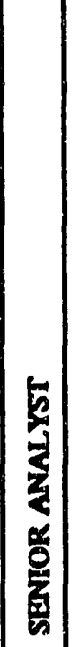 & 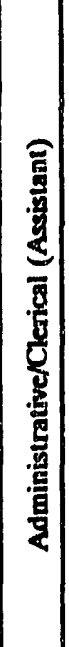 & 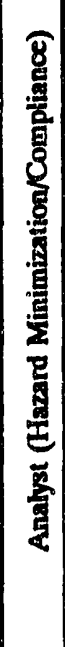 & 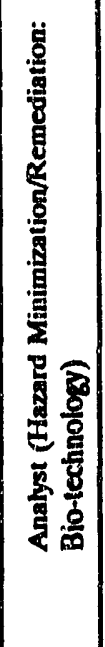 & 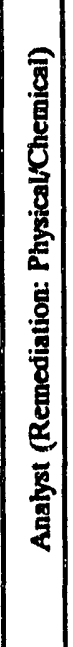 & 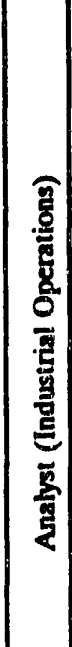 & 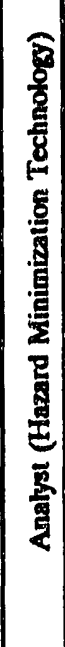 & 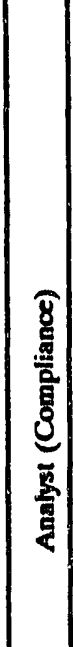 & 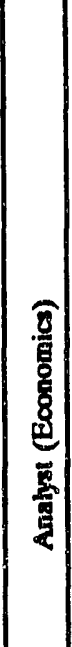 & 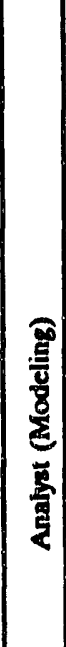 & 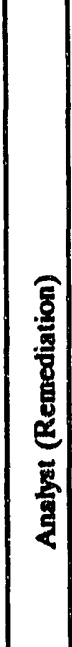 & 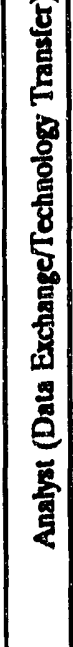 & 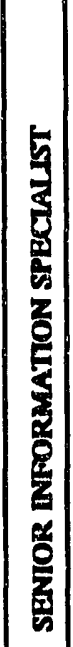 & 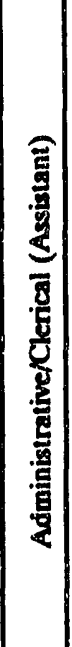 & 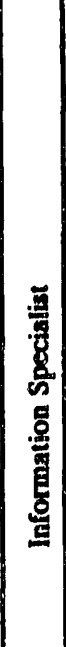 & 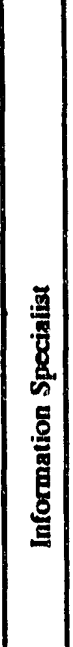 & 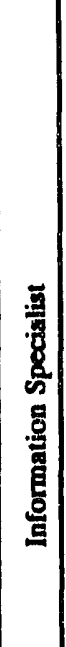 & 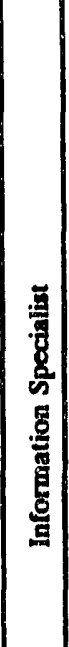 & 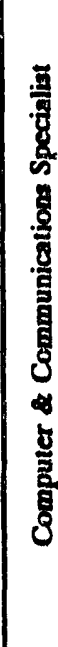 & | \\
\hline
\end{tabular}


Government salaries are estimated using the 1992 DoD pay charts. Consultant salary rates during Phase 1 are estimated using a 1.7 overhead multiplier. Base salaries for contractor personnel are assumed to be $\$ 75 \mathrm{~K}$ for senior analysts and $\$ 50 \mathrm{~K}$ for information/computer specialists. Fully burdened rates for the prime contractor are calculated with an assumed multiplier of 2.0 .

\subsection{Nonlabor Costs}

Tables 6.3-A and 6.3-B show acquisition costs of EQIAC hardware and software during the three implementation phases. Unit costs of items (wherever applicable) are also provided so that acquisition cost estimates for various options can be determined. Most of the hardware cost estimates are based on information provided by the Digital Equipment Corporation.

Phase 1 is estimated to be the most expensive for hardware and software acquisition; costs total $\$ 283 \mathrm{~K}$. Total costs during this phase will be significantly less (i.e., no cost for the on-line bibliographic software) if the on-line bibliographic software is the replacement for the existing old version of the same software currently in use by the TIC. During the subsequent two phases, total acquisition costs are significantly less, in the range of $\$ 40 \mathrm{~K}-\$ 60 \mathrm{~K}$. The higher acquisition cost during Phase 3 than Phase 2 is due to upgrading of the hardware platform in Phase 3. 


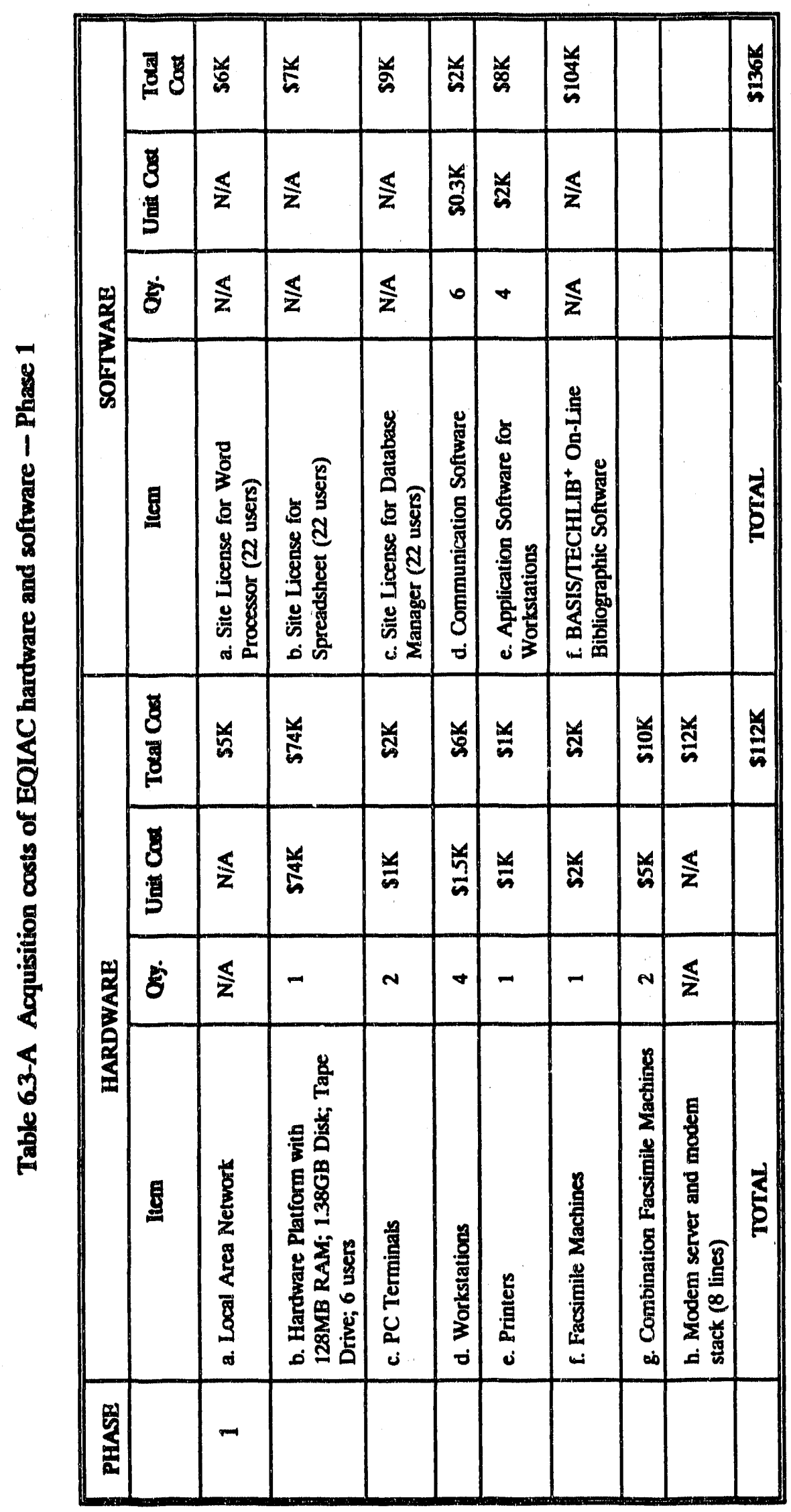




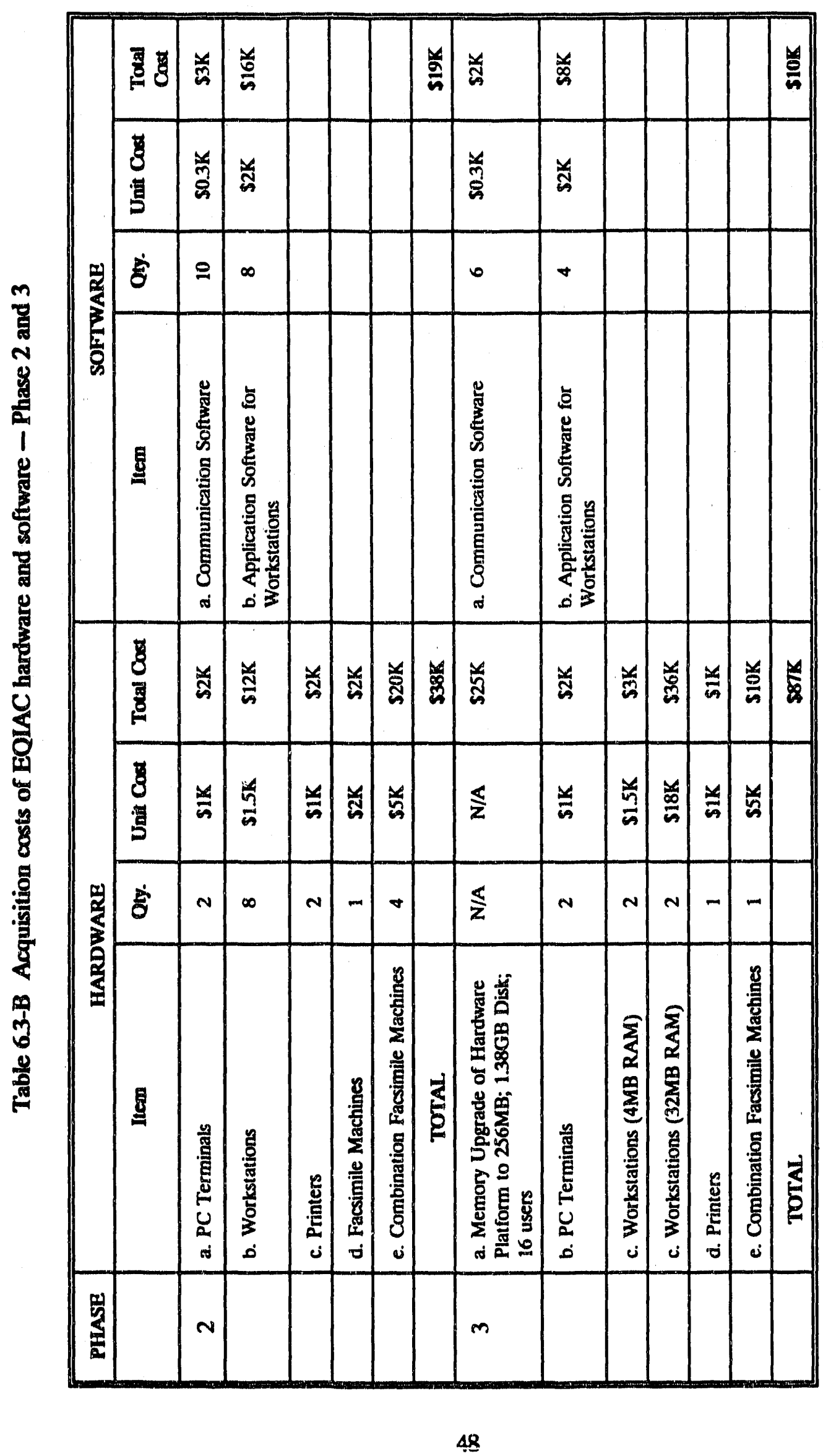




\section{SUMMARY AND RECOMMENDATIONS}

This document outlines the demand for environmental quality technology in the federal sector. Moreover, using the case study for an Air Force EQIAC developed in Sects. 1.5 and 3.0, a plan for its development is outlined in Sects. 4.0 and 5.0. However, the scope of the needed technology information service and the resources required to develop and maintain the full-scale technical capabilities effectively to meet that demand are beyond the capabilities of any single agency. These information services can be provided through a distributed EQIAC using the nodal approach described in Sect. 4.1. Through a nodal approach, the required resources can be provided by various federal organizations.

Section 7.2 outlines a set of recommendations for developing a national center to provide support in environmental technology information throughout the federal government and provides some specific recommendations for the Air Force EQIAC initiative in Sect. 7.3.

\subsection{SUMMARY OF THE EQIAC PLAN}

The federal demand for environmental technology information was outlined in Sect. 1.0. The principal drivers for this information are the compliance requirements of environmental legislation, facility modernization and decommissioning (and DoD base closures), and the need to minimize the costs of environmental operations. Effective environmental programmatic decisions, including decisions in program planning and budgeting for environmental compliance in federal programs, require this information to meet compliance requirements. Technology information is also needed to identify and forecast technology needs to meet environmental requirements, to define environmental technology R\&D needs, and to carry out the transfer of environmental technology and environmental technology information.

The demand for information was grouped in two categories:

- Near-term decision support (technology information and analysis for logistical operations) and

v Long-term decision support (technology information for prograin planning, budgeting, and technology acquisition).

A review of existing IACs in Sect. 2.0 outlines the structures of and the types of services being provided by comparable IACs in other technology areas. Based on this information, strategic and operational objectives for a proposed Air Force EQIAC were developed in Sect. 3.0. The Air Force case study was developed in the remaining sections by providing the EQLAC description in Sect. 4.0 and system requirements and costs estimates for its implementation in Sect. 5 and Sect. 6, respectively. The case study of the AFCESA outlines the implementation of an EQLAC with limited scope and provides the basis for a much broader multi-agency-supported center. 


\section{GENERAL RECOMMENDATIONS}

The results of this study suggest the following recommendations for a national center for environmental technology information and expertise:

\section{Recommendation \#1}

A multi-agency-supported, national center for lechnical support diagnosis, and systems analysir of emvironmental problems and for the management, assessmitnt, and distribution of eovinonmental quality technology information should be establisbed by a federal agency or as a multi-agency consortium.

Such a center would be consistent with the demand, objectives, and structure outlined in Sects. 1.0 through 4.0 of this study. Given the vast amount of information available and the resources required to manage and maintain it, such a center can be viable only a multi-agency-supported effort. Although all federal agencies need the services of such a center, the primary participants should include DOE, EPA, and DOD with the Army, Navy, and Air Force as individual primary participants. Each of these organizations has the mandate and organizational resources to initiate and lead such an effort. However, DOE and EPA seem to have the existing structure, ongoing related technology efforts, and preliminary technical resources to be more effective in initiating this center.

\section{Recommendation 2}

This center should coordinate all foderal eavirunmental technology information sources and develop an effective networt to acces, maintain, and distribute environmental technology information in timeframe necessary to soeet federal eavirommental operational requirements.

This capability is consistent with the "near-term decision-support" objective of the EQIAC outlined in Sect. 3.0. It is a focused "quick response" technology information capability needed by all federal agencies. This center would coordinate the transfer of information not only to federal agencies but also to state, local, and private organizations involved in environmental cleanup and remediation. The center, as distributed, technology-specific nodes, could play an important role as the national coordinator for non-EQIAC organizations with resisurces and capabilities in environmental quality technology.

\section{Recommendation *3}

The center should focus on coordinating and/or mupporting the development of methodologies and syatems to characterize and analyzat environuental problems and to support technology information needt for planning and analyzing federal agenciex" environmental program requirements.

This capability should be consistent with the objectives and organizational capability outlined in Sects. 3.0 and 4.0 of this plan. This function is required in the program planning and budgeting of all agencies; a centralized information base that avoids duplication of effort not only would be more cost effective, but would ensure that the most effective andl appropriate technology is available to all agencies. 


\section{Recommendation \#4}

The center should be developed incrementally by technology demand area and according to a phased approach that allows for controlled growth. It should be developed in a manner most responsive to federal agencies' needs.

Incremental growth could occur according to the types of environmental products and services in demand. For example, a first increment of technical capability in site restoration could be biotechnologies and technologies dealing with mixed wastes. A second increment could be pollution control technologies; a third could be technologies for compliance by type of industrial or process operation, etc. Many of these increments can be considered "nodes" in a technology information network, where each node would exist in the organization that has an existing capability or is naturally favored to develop it. The phased implementation would allow for controlled growth that would help ensure the development of the most appropriate capabilities, based on continually defined user demand.

\subsection{RECOMMENDATIONS FOR AN INTIIAL AIR FORCE EQIAC}

Given this demand for service and the inherent limits of organizational growth, the following recommendations, supplemental to the structure outlined in Sect. 4.0, are suggested:

\section{Phase 1: Initial Operational Capability}

- Concentrate on developing technology expertise to support Air Force environmental quality activities in site restoration and pollution prevention technologies.

- Identify and hire initial staff who can perform the multiple functions required in the initial stage of the EQIAC. This includes staff with site restoration and pollution prevention technology expertise and data base development expertise to support program planning capabilities.

- Concentrate on the development of close working relationships with other key organizations in order to know their needs and obtain fiscal support. For example, AFCEE and DOE/EM might establish a formal DOE/Air Force interagency agreement and promote the EQIAC beyond the AFCESA but within the Air Force.

Phase 2: Interim Operational Capability

- Expand the technical expertise of the EQIAC to allow expanded service to other DoD organizations.

- Initiate routine "task order" analysis with other DoD services beyond the Air Force.

- Begin to develop working relationships and, when possible, interagency agreements with other federal and state agencies. 
Phase 3: Full Operational Capability

- Initiate the development of modeling capability for technology requirements forecasting.

- Expand and maintain data bases and/or information access in targeted technology areas.

- Initiate the development of the technology center node concept with other organizations. 


\section{APPENDIX A}

\section{A REVIEW OF EXISTING IACS}




\section{A REVIEW OF EXISTING IACs}

effort.

The following is a brief description of the IACs reviewed as a part of this multi-year planning

\section{The Carbon Dioxide Information Analysis Center}

The Carbon Dioxide Information Analysis Center (CDIAC) is part of the Environmental Sciences Division of the Oak Ridge National Laboratory, and it has been operational since 1982. The CDIAC provides information support on the complex environmental issues associated with elevated atmospheric $\mathrm{CO}_{2}$. This includes issues associated with global climate change. Clients being served by the CDIAC include the international research, policy, and education communities. Of these, the heaviest users currently are the research and policy groups, respectively. CDIAC is videly accepted within the research community and has become a vital tool to policy makers both domestically and internationally. Publications put out by the CDIAC such as the Glossary of Carbon Dioxide and Climate have become standard references for researchers across all disciplines.

CDIAC was established in 1981 at a funding level of $\$ 200 \mathrm{~K}$ to solve the problem of inadequate communication within the area of carbon dioxide research among the climatologists, geographers, chemists, and others working in this specialized field. An original client roster was identified by developing a list of all the known researchers and policy makers in this area. Newsletters were then sent to each one that presented information on important or controversial topics. As reader acceptance grew, CDIAC introduced a Numeric Data Package (NDP) and Computer Model Packages (CMP). These are data sets and models developed by researchers in the area, which the CDIAC accepts for distribution to interested parties. The data sets and models are quality assured and documented so that they can be used by others both within and outside the group of developers.

The major difference between CDIAC and EQIAC is that CDIAC does not perform bibliographic or data searches on demand for its client base, whereas EQIAC expects this to be a significant fraction of its efforts. CDIAC performs substantial data collection and dissemination in its area of emphasis, but the method of dissemination is largely through publication of reports and newsletters. Its computer communications systems are used largely for receiving requests for existing data sets and models.

CDIAC is very successful in this publishing mode of client service, and EQLAC should pay attention to this methodology, especially with respect to two of CDLAC's products: the Computer Model Packages (CMP) and the bibliographic compendia. These products are distributed free by CDIAC. After EQIAC is started with stable funding, it would be advisable to generate analogous products and distribute them without charge to authorized users and, when appropriate, to prospective users as a method of building a wider audience than would be likely if a nuisance-level charge were levied. Some of the well-established DoD IACs supplement their operating budget with income from handbooks of data or bibliographies, but it rarely is a major source of revenue.

The most likely supplemental revenue source for EQIAC would be special studies and tasks performed in support of DOD and DOE offices who would pay for them on a case-by-case basis or by an annual support stipend to cover anticipated usage. CDIAC's compilation of directories of researchers is an activity that helps cement its position at the center of its field of expertise. Most 
IACs have an internal list of experts that they call upon to assist in special studies, but they do not attempt to compile such lists for purposes of networking and referral within the community. This is a tool that appears useful for EQIAC to consider.

In conclusion, while these two IACs seem to be different in many respects, they have much in common, and there is much that EQLAC can learn from CDIAC. The most important lesson may be that it takes time to develop. It was a full 5 years before the CDIAC was able to function on its own and become an important tool. During this first 5 years, they experimented with many different products and approaches; some worked and many did not. The EQIAC must also go through this development stage. It must work to find out what its users want, and how best the IAC can provide it. This will take time and support from sponsors. With these two vital elements, the EQIAC has a much better chance of filling an important place in the area of environmental quality studies.

\section{The Supportability Investment Decision Analysis Center}

The Supportability Investment Decision Analysis Center (SIDAC) is an Air Force IAC planned for initial operational capability in 1992. The SIDAC is a joint venture by the Air Force Logistics Command (AFLC) and the Air Force Systems Command (AFSC), which will share the cost of the core operations of SIDAC. SIDAC will have an Air Force program manager and will be contractoroperated from a location within a few miles of Wright Patterson AFB, Ohio.

The SIDAC mission is to focus on weapon systems and technology managers' needs for quality decision support services when investing resources in the supportability of systems. This will be accomplished by several mechanisms, a major one being that of serving as a repository of governmentowned models for the supportability costs of weapons systems. SIDAC will provide technical assistance to the supportability community, which is a very diverse customer base encompassing communities of R\&D, systems, and the logistics infrastructure. SIDAC will promote the efficient development, storage, and distribution of supportability-related methods, models, and techniques. Conferences and technical seminars will be used to cross-communicate between the various user communities the SIDAC will serve.

The Air Force Reliability and Maintainability (R\&M) modeling needs had been evolving for a decade from a variety of activities that included the issuance of Weapon System Master Planning Policy, AFLC's Functional Management Inspection, the Aeronautical Systems Division R\&M Study, the Scientific Advisory Board's Reliability, Maintainability and Logistics Report of 1987, and the AFLC R\&M Modeling Conference of 1988. This latter conference, a product of the collaboration, gathered the tactical logistics models that were available or in development and identified voids and requirements for new capabilities. The recommendation from the conference was that the supportability community should take an institutional approach to focusing these efforts. This was the genesis of the SIDAC concept.

A concept definition study in 1988 led to a series of advocacy briefings for organizations with a vested interest in supportability. They responded with a clear call for the following services, in order of importance:

1. An information base

2. Technical support

3. Modeling services
4. Data services

5. Communication services

6. Methodology services 
Among the features of these services deemed most important by the interviewees were credibility, responsiveness, quick reaction, completeness of services, and availability of training.

The concept definition phase was guided by an intercommand steering group that provided strong advice and counsel regarding the scope and direction of SIDAC, including financial, management, and technical issues. An unequivocal endorsement of the SIDAC implementation was given by the Concept Definition Steering Group.

The procurement methodology for SIDAC is designed to allow the features mentioned above that were deemed most important by the users, namely quick reaction, responsiveness, and a full spectrum of services. The Request for Proposal (RFP) calls for three components of the award having different funding mechanisms. The core services must be firm fixed price; the extended services will be cost-plus-fixed-fee; and the special tasks will be customer funded under delivery order for each special task. The contractor must be able to perform the core tasks plus a minimum number of the extended services in-house with its own staff. The other extended services and the special tasks may be performed by other firms used as subcontractors to the IAC prime contractor.

The importance of the special tasks to the IAC cannot be underestimated. The core funding will be $\$ 500 \mathrm{~K}$ for the first year (the award will be for 1 year with four more 1 -year options), while the total ceiling for the award will be \$70M. Clearly, the intent is for the gaps in modeling identified by the IAC to be corrected by major modeling development efforts under the IAC contract, performed in conjunction with other subcontractors when needed.

Satisfying the competition-in-contracting up front like this enables rapid implementation of the corrective efforts. The above methodology has historically been used by the DoD IACs. The reexamination of the methodology by DLA and DESC that delayed the SIDAC procurement is reportedly resolved, so this key attribute of IACs appears to have current approval.

There are several similarities between SIDAC and EQLAC. Both cover an extremely broad topical area. Both have a joint sponsorship interest from two major organizations (AFLC and AFSC in the case of SIDAC, and DoD and DOE in the case of EQIAC). Both have a host site that would commit government personnel and facilities to team with contractor personnel to staff the IAC (AFLC in the case of SIDAC, and AFCESA in the case of EQIAC). Both envision an operation methodology that recognizes the imperative of cooperating with and drawing upon many other centers having excellent technical capability and possessing relevant databases that should not be duplicated. Electronic networking with these other centers of information and with the user community is an important feature for both SIDAC and EQIAC. There is even a rationale for communication and cooperation between SIDAC and EQIAC based on the importance of hazardous materials in considering the supportability costs of systems and facilities. The SIDAC Program Manager has expressed an interest in developing this interaction as the EQLAC progresses.

At least three important conclusions can be drawn from the SIDAC experience that are relevant to EQIAC. First, early contact and involvement by the user community in the structuring of the EQIAC is critical to assuring their favorable evaluation and fiscal support. This is especially so for those users who are also major centers of information themselves.

Second, the clarification of the contracting mechanism to allow for rapid obligation of funding for special studies and tasks, especially those involving subcontractors, must be done through 
discussions with the contracting office that will be asked to do the procurement. Unless such a mechanism is approved, the responsiveness demanded by the users will be hampered severely, possibly to the point that the EQLAC would not be viable given the extremely broad technical coverage needed to handle the EQIAC tasking.

Third, if the goal EQIAC is to be a DoD IAC, the approach of initiating the EQIAC appears correct, especially given the recent reporting changes for the existing DoD IACs.

\section{The High Temperature Materials Information Analysis Center}

The High Temperature Materials Information Analysis Center (HTMIAC) serves as the DoD central source of engineering data and technical information on high temperature material properties, especially the properties of aerospace structural composites and metals and infrared detector/sensor materials. Although generally useful for DoD weapons systems and hardware R\&D, this data is especially useful for assessments and studies of the vulnerability, survivability, and hardening of military structures with respect to high energy lasers and other directed energy weapons.

The HTMIAC was established on 1 January 1986 and has been operated by Purdue University since that time. HTMIAC is a Defense Technical Information Center (DTIC) IAC and managed at DTIC with the Contract Officer's Technical Representative (COTR) at the Pentagon in the Office of The Undersecretary of Defense For Research and Engineering, Research and Advanced Technology, OUSDR\&E(R\&AT/ET).

The COTR chairs the Tri-Service Laser Hardened Materials and Structures Group (LHMSG) which, together with the high energy laser community associated with the Strategic Defense Initiative, are the primary clients for HTMIAC. Only qualified users approved by this group can access the HTMIAC data base. Their requests are serviced by telephone and mail, with the searches being performed by the HTMIAC staff and the results being phoned, faxed or mailed to the requestors. Classified limited distribution documents are generally mailed to the requestor from the classified library holdings at HTMLAC.

The exception to this very limited distribution policy of HTMIAC is the High Temperature Materials Properties Database (HTMP). This is an unclassified on-line subset of the HTMIAC data base hosted on a VAX computer at HTMIAC. Access is permitted to registered DTIC users who subscribe to the service. Over 14,000 sets of data covering over 600 materials can be remotely accessed in two modes of use, depending on the sophistication of the user. A menu driven mode services the infrequent user, while experienced users can pre-define their search strategy for more rapid access.

The most important conclusion from the HTMIAC experience is that significant effort must be devoted to stay in touch with the evolving needs of the user community. The IAC that preceded HTMLAC had performed a high quality service for decades, but drifted apart from the pressing needs that arose among its users. HTMIAC was created to service the emerging needs of the Laser Hardened Materials and Structures Group, which now provides continuing guidance to HTMIAC on user needs. The EQIAC should establish user group communications mechanisms to assure continuing relevance of its services.

HTMIAC also shows that ad-hoc funding from interested users can lead to a proof of value and eventual long term institutional funding. 
The major difference between HTMIAC and EQIAC is that EQIAC will exist in a network of other centers of data and expertise and will permit significantly greater access. A more sophisticated communications system will be needed to exchange information and data with these diverse users. The communications network should provide one of the channels of user input regarding the continuing relevance of EQIAC to its client community.

\section{The Metals Information Analysis Center (MIAC) and the Ceramics Information Analysis Center (CIAC)}

The Metals Information Analysis Center (MIAC) and the Ceramics Information Analysis Center (CIAC) are IACs that cover selected metals and ceramics, respectively, for the DoD laboratories and contractors. They were originally combined and known as the Metals and Ceramics Information Analysis Center (MCIC), which had a distinguished record of continuous service to DoD for 35 years. Since 1990 they have been operated separately by the same contractor, Purdue University.

The MCIC was started in 1955 and was operated by Battelle in Columbus, Ohio, with distinction until 1990. In August of 1990 , Purdue University was chosen to operate the MIAC at $\$ 300 \mathrm{~K}$ per year of core funding, and the CIAC at $\$ 400 \mathrm{~K}$ per year of core funding for five years (a 3-year contract with two 1-year options). Both IACs support the Joint Logistics Commanders/Joint Directors of Laboratories Technology Initiative Panel for Advanced Materials. Their COTR is in the Office of the Director of Defense Research and Engineering, Research and Advanced Technology (ODDR\&E (R\&AT/ET)).

The normal modes of service from MIAC and CIAC are by telephone, overnight mail, regular mail, or telefax service in response to telephone or mail inquiry. They also file their technical holdings in the DTIC DROLS on-line system for direct access by DTIC qualified users.

Both the CIAC and MLAC are making a concerted effort toward the creation of new databooks on focused topics. Sixteen topics have been identified as candidates for handbooks, and workshops are being used to determine the level of user interest and the content of the handbooks. In another initiative to create new products, the MIAC and the Air Force have agreed to enter into a Cooperative R\&D Agreement (CRDA) to computerize and update three reference books that have historically been used extensively by the aerospace and related industries: Aerospace Structural Metals Handbook, the Structural Alloys Handbook, and the Damage Tolerant Design Handbook. Under the terms of the agreement, the regular maintenance, updating, and publication of these handbooks will become self-supporting, with a return of royalties to the government. Distribution will be by floppy disk in addition to the traditional hardcopy.

The MIAC and CIAC offer a good example of the classical contractor-operated, contractorlocated DoD IAC. They perform the bibliographical reference service desired of an IAC, but do it without much in the way of on-line networking. Rather, they insert their holdings into the DROLS system and let all qualified DTIC users access their holdings by that on-line system. It may be useful for EQIAC to explore, together with the other relevant repositories, whether one or more centers that already have on-line systems would host the holdings of some of the other centers. In the MIAC and CIAC case, this allows them to focus on the direct requests for special searches from users who do not have a search librarian. 
The new emphasis on workshops and handbooks (especially personal computer versions) is a good strategy for EQIAC to consider as a means of building visibility in the community.

The "Analysis" part of the IAC function is one that the Purdue staff have always stressed; that is, they plan to have a pedigreed bibliography as well as the comprehensive bibliography. This requires having staff researchers make judgements as to which publications are worth including in the "recommended" bibliographic data base and in the handbooks. This is more than just a library cataloging function and is crucial to user acceptance and support.

The five-year funding cycle for the core support is long enough that projects such as the handbooks can be undertaken with a good likelihood of successful completion. This level of stability is strongly recommended for EQIAC.

\section{The Environmental Technical Information System}

The Environmental Technical Information System (ETIS) is part of the U. S. Army Construction Engineers Research Laboratory (USA/CERL). The ETIS provides technical and information support on the identification of potential environmental impacts, economic impact forecasting, environmental legislation, hazardous material management support, and computer communication through a bulletin board.

The ETIS is not a system to track technologies. It is an on-line information system designed to provide a "library" information support function, but it does not provide the analysis support functions proposed for the EQIAC. USA/CERL has contracted to the University of Illinois in Champaign, Ill. The University has formed the Environmental Information Connection (EIC) to provide support services to users of the ETIS. These services include literature searches, bibliography preparation, obtaining database and software information, investigating information sources, selective dissemination of information, and locating specialists or information centers.

The ETIS is managed by the University of Illinois Department of Urban and Regional Planning. The ETIS is coordinated by the CERL for use by the Army and other DoD services. It was originally funded by the Army and the DOE and has now evolved into a self-supporting system paid for by the membership through an initial subscription fee, per-hour user connect charges, and per-hour staff time for technical support and other small user charges.

There are several major differences between the functions of the ETIS and the proposed EQIAC. The principal difference is that the ETIS provides user access to information bases, but it does not provide the user support technology analysis and applications. The key difference is that the ETIS does not have the IAC operation that includes technical staff and technical support contractors proposed for the EQIAC.

A strong possibility exists for collaborative funding of EQIAC by ETIS, which should be pursued through mechanisms that could include ETIS personnel co-located at EQIAC. 
APPENDIX B

EXAMPLES OF ENVIRONMENTAL TECHNOLOGY DEMONSTRATIONS 


\section{EXAMPLES OF ENVIRONMENTAL TECHNOLOGY DEMONSTRATIONS}

This appendix contains examples of environmental technology demonstrations by the EPA, DOE, Air Force, and Army. The examples include:

- EPA technology demonstrations in bioremediation,chemical treatment, dechlorination, in situ flushing, in situ vitrification, soil washing, solvent extraction, and thermal desorption.

- DOE's Integrated Demonstrations of Environmental Technologies in groundwater and soils clean-up, waste retrieval, waste processing, and waste minimization.

- Air Force technology development in hazardous Waste minimization, pollution control, and site restoration.

- Army technology development in installation restoration, pollution prevention, and base support operations. 


\section{EXAMPLES OF EPA TECHNOLOGY DEMONSTRATIONS}

Bioremediation (Ex situ) Technologica

\begin{tabular}{|c|c|c|}
\hline Specific Technolod & Site Description & Koy Contaminnists Treated \\
\hline Land ireatment & Industrial Complex \& Rail-yard Wastes & $\begin{array}{l}\text { Petroleum Hydrocartons, VOCs } \\
\text { (BTEX), and PAHs }\end{array}$ \\
\hline Land ireatment & Chemical Formulation & Carcinogenic PAHS \\
\hline Solid-phase bioremediation & Oil Recycling & $\mathbf{P C P}$ \\
\hline $\begin{array}{l}\text { Excavation/on-site bioremediation - type } \\
\text { to be determined }\end{array}$ & $\begin{array}{l}\text { Waste Dispoal for Charcaal } \\
\text { Manufacturing Plant }\end{array}$ & $\begin{array}{l}\text { Tar, PAHs, VOCs (BTX and PCE), and } \\
\text { SVOCs (Phenol) }\end{array}$ \\
\hline Land treatment & Oil Refining \& Waste Oil Reclamation & $\begin{array}{l}\text { Petroleum Hydrocarbons and VOCs } \\
\text { (Benzene, Ethylbenzene), }\end{array}$ \\
\hline Land treatment of solls/sludge & Railyard Wastes (Industrial Wastewater) & $\begin{array}{l}\text { Phenols, Petroleum Hydrocarbons, and } \\
\text { Diesel Fuel }\end{array}$ \\
\hline Slurry-phase bioremediation & Commercial Waste Disposal & $\begin{array}{l}\text { VOCs (Benzene, Toluene) and SVOCs } \\
\text { (Phenols) }\end{array}$ \\
\hline Land treatment & Paint Manufacturins Wastes & VOCs (Methyl Etbyl Ketone and BIX) \\
\hline $\begin{array}{l}\text { Land ireatment in conjunction with coll } \\
\text { dushing }\end{array}$ & Commercial Waste Managenent & Phenols and Creapl \\
\hline $\begin{array}{l}\text { In situ groundwater bioremediation } \\
\text { (Aren D only) }\end{array}$ & Jet Fuel Tank Farm & VOCs (BXEX) \\
\hline $\begin{array}{l}\text { In aitu soil and groundwater } \\
\text { bioremedintion }\end{array}$ & $\begin{array}{l}\text { Wante Disposal for Charcoal } \\
\text { Manufacturing Plant }\end{array}$ & $\begin{array}{l}\text { VOCs (BTX), PAHs, and SVOCs } \\
\text { (Phenols) }\end{array}$ \\
\hline In situ soil bioremediation & Municipal LandזIll & $\begin{array}{l}\text { VOCs (TCE, BTEX, DCE, TCA, } \\
\text { DCA) and SVOC (Naphthalene) }\end{array}$ \\
\hline In aitu soil bioremediation & $\begin{array}{l}\text { Chemical Waste Mansgement and } \\
\text { Incineration }\end{array}$ & $\begin{array}{l}\text { Petroleum Hydrocarbons, BTEX, and } \\
\text { various SVOC. }\end{array}$ \\
\hline In situ soll bioremediation & Raityard Wastes (Industrial Wastewater) & $\begin{array}{l}\text { Phenols, Petroleum Hydrocarbons, and } \\
\text { Dieael Fuel }\end{array}$ \\
\hline In eitu Ingoon bioremedintion & Petrochemical & $\begin{array}{l}\text { VOCs (BTEX), PAHE, Petroleum } \\
\text { Hydrocarbons, and PCB. }\end{array}$ \\
\hline In situ groundwater bioremedistion & Solvent operation & $\begin{array}{l}\text { VOC (Total, Acetone, Ethylbenzenes, } \\
\text { TCA, and Xylenes) and SVOCs } \\
\text { (Dichlorobenzene) }\end{array}$ \\
\hline
\end{tabular}


Chemical Treatment

\begin{tabular}{||l|l|l|}
\hline Specific Technology & Site Description & Key Conteminants Treated \\
\hline $\begin{array}{l}\text { Reduction of Cr(VI) to CR(III) } \\
\text { Followed by Solidification) }\end{array}$ & Wood Preserving & $\begin{array}{l}\text { Metals (Chromium, Arsenic, and } \\
\text { Copper) }\end{array}$ \\
\hline $\begin{array}{l}\text { Chemical Oxidation with Sodium } \\
\text { Hypochlorite }\end{array}$ & Silver recovery facility & Cyanide \\
\hline $\begin{array}{l}\text { In aitu Chemical Treatment using } \\
\text { codium hydroxide }\end{array}$ & Inactive airfield with buried drums & $\begin{array}{l}\text { Taxaphene, Ethyl Parathion, and Methyl } \\
\text { Parathion }\end{array}$ \\
\hline
\end{tabular}

\section{Dexblorination}

\begin{tabular}{||l|l|l||}
\hline Specific Technology & Sitc Description & Key Contamimants Treated \\
\hline $\begin{array}{l}\text { Dechlorination of Residuals from } \\
\text { Thermal Desorption }\end{array}$ & Chemical Reclamation Facility & PCBs \\
\hline $\begin{array}{l}\text { APEG dechlorination using anaerobic } \\
\text { thermal process unit }\end{array}$ & $\begin{array}{l}\text { Contaminated Road Dust, Driveways, } \\
\text { and Ditches }\end{array}$ & PCBs \\
\hline Dechlorination & Operation and maintenance facility & Dioxins (2,4,5,1) \\
\hline APEG - Plus Dechlorination & Transformer and Solvent Recycier & PCBs \\
\hline Dechlorination & Salvage yard and induatrial waste dump & PCBs \\
\hline KPEG Treatment & Electropiating Gacility & Herbicide (silvex, 2,4,5 TP) \\
\hline
\end{tabular}

\section{In Situ Fluning}

\begin{tabular}{|c|c|c|}
\hline Specific Technology & Sile Description & Key Cootuminants Treated \\
\hline In situ soil flushing & Uncontrolled Dump Sitc and Landfill & VOCs (PCE, TCE, DCE, and DCA) \\
\hline In situ flushing & Commercial Dump Site & $\begin{array}{l}\text { VOCs, Phenol, and Metals (Chromium, } \\
\text { Nickel, Lead, and Mercury) }\end{array}$ \\
\hline In situ diseolution of waste & Titanium Diaxide Plant & Fermous Sulfate \\
\hline $\begin{array}{l}\text { In aitu soil fuehing (After Vacuum } \\
\text { Extraction) }\end{array}$ & Solvent Recovery and Storage Facility & $\begin{array}{l}\text { PCBs and Metals (Arrenic, Barium, } \\
\text { Cadmium, Chromium, Lead, Mercury, } \\
\text { Selenium, and Silver) }\end{array}$ \\
\hline In situ soil flushing & Commercial Dump Site & $\begin{array}{l}\text { VOCs (BTEX, TCE), PAHs, Phenolw, } \\
\text { Lead, PCBs, and other Metals }\end{array}$ \\
\hline $\begin{array}{l}\text { Soil Flushing in conjunction with Land } \\
\text { treatment }\end{array}$ & Commercial waste management & Phenols and Cresol \\
\hline In situ flushing & Chrome Plating Facility & Chromium \\
\hline
\end{tabular}


In Skttu Vitrification

\begin{tabular}{|c|c|c|}
\hline Sperific Totholog & Sits Description & Key Contaminarate Treated \\
\hline $\begin{array}{l}\text { In situ Vitrification (Thermal desorption } \\
\text { beimg comaidered) }\end{array}$ & $\begin{array}{l}\text { Cherwical Manutacturing Facility Wante } \\
\text { Lagoon }\end{array}$ & $\begin{array}{l}\text { MBOCAs (4' Methylene Bis- } \\
\text { dichloroaniline) }\end{array}$ \\
\hline In situ Vitrification & Municipul Landtill & $\begin{array}{l}\text { VOCs (Methyiene Chloride, Styrene, } \\
\text { Toluene, 1-1-1 Trichloroethane), and } \\
\text { Lead }\end{array}$ \\
\hline $\begin{array}{l}\text { In aitu Vitrification (Alternative is } \\
\text { incinention) }\end{array}$ & Federal Facility & PCBe and Metais (Lead and Cadmium) \\
\hline In altu Vitrification & Federal Facility & $\begin{array}{l}\text { Metaks (Arsenic and Mercury) and } \\
\text { Pesticides }\end{array}$ \\
\hline
\end{tabular}

Soil Wabing

\begin{tabular}{|c|c|c|}
\hline Spacifo Teatroology & Sile Description & Key Contaminanate Treated \\
\hline $\begin{array}{l}\text { Soll Weahing (preceded by Solvent } \\
\text { Extraction) }\end{array}$ & Industrial Waste Dumping & $\begin{array}{l}\text { VOCs (BTX), sVOC (Naphthalene } \\
\text { and 2,4-dimethylphenol) and Metals } \\
\text { (Chromium and Lead) }\end{array}$ \\
\hline Hydromerallwratical Troatment & Wiring Service Facility & Mercury \\
\hline Soll Weahing & Recycling & Metals (Chromium, Copper, and Sitver) \\
\hline Soll Wayming & Lead Battery Reoycling & Lead and Amenic \\
\hline
\end{tabular}

\section{Solvene Eratunctian}

\begin{tabular}{|c|c|c|}
\hline Spectite Todimalong & Sile Deucription & Koy Contaminante Trealad \\
\hline Solvent Extraction & Indiaturial Waste Dumping & $\begin{array}{l}\text { PCBe, PAHs and VOC. (TCE, } \\
\text { Trichlorobenzene) }\end{array}$ \\
\hline Solveat Extraction & $\begin{array}{l}\text { Salvate \& Electrical Tramsformel: } \\
\text { Recycling }\end{array}$ & PCB, PAHts, and Lead \\
\hline Solvent Extribction & Salvage aud Vehicle Repair & $\begin{array}{l}\text { PCBa, VOCs (Chlorobenzeme), SVOCs } \\
\text { (Dichlarobentene and } \\
\text { Trichlorobenreae) }\end{array}$ \\
\hline $\begin{array}{l}\text { Solvent Eximetion (follomed by Soil } \\
\text { Wuehing) }\end{array}$ & Imduetrial Waste Dumping & $\begin{array}{l}\text { VOCs (BTX), SVOCi (Naphulimaleace } \\
\text { and 2,4-dimethytphenol), and Metal }\end{array}$ \\
\hline $\begin{array}{l}\text { Bevic Extrnetive Sludige Trentment } \\
\text { (BEST) }\end{array}$ & Waste oil recyeling facility & $\begin{array}{l}\text { PCBs, Metals (Anenic, Copper, and } \\
\text { Lead) }\end{array}$ \\
\hline Solveal Exteration & Stornge tanagement complen. & PCBs \\
\hline
\end{tabular}


Therrand Desorption

\begin{tabular}{|c|c|c|}
\hline Specific Technolow & Site Description & Key Contsminants Theated \\
\hline Thermal Aeration & $\begin{array}{l}\text { Chemical Waste Handling, Storage, \& } \\
\text { Incineration Facility }\end{array}$ & $\begin{array}{l}\text { VOCs (Benzene, TCE, and Vinyl } \\
\text { Chloride) }\end{array}$ \\
\hline Thermal Aleration & $\begin{array}{l}\text { Waste Stomge, Tranufer, Disposal } \\
\text { Facility }\end{array}$ & VOC (TCE, BTX) \\
\hline Thermul Aeration & Drum Reconditioning Facility & $\begin{array}{l}\text { VOCs (TCE, PCE, 1,2-DCA, and } \\
\text { Benzene) }\end{array}$ \\
\hline $\begin{array}{l}\text { Rotary Thermal X'TRAX Desorber } \\
\text { (Dechlorinution of residues) }\end{array}$ & Chemical Reclamation Facility & PCBe \\
\hline Thermal Desorption & Thermostat Manufacturing & $\begin{array}{l}\text { VOCs (PCE, TCE, DCE, and Vimyl } \\
\text { Chloride) }\end{array}$ \\
\hline Low Tempernture Vaporization & Unpermitted Septic Waste Facility & VOCs (TCE, PCE, and TCA) \\
\hline Thermal Desorption & Chemical Facility & $\begin{array}{l}\text { DDT, DDD, DDE, VOCs (DCE, PCE, } \\
\text { TCE, and Toluene), sVOCs (Benzoic } \\
\text { acid, BIS(2-ethylhexyl)phthalate, Buttyl } \\
\text { benzyl phthalate, Di-n-butyl phthalate, } \\
\text { Naphthalene, and PCP], and PAH. } \\
\text { (Benzo(a)pyrene) }\end{array}$ \\
\hline Low Tempernture Thermal Treatment & Former Waste Tank Farm & $\begin{array}{l}\text { VOCs (Xylene, Styrene, TCE, } \\
\text { Elhylbeareate, Toluene) }\end{array}$ \\
\hline Enhanced Volatilization & Former Ballery Manufacturer & VOC (PCE, Toluene, and TCE) \\
\hline Low Tesperature Thermal Treatmeni & Metal Manurfacturing & VOC (TCE) \\
\hline Enmasced Volatilizatiou & Uncontrolled Warte Dinpoenal & VOC and Semivolatiles \\
\hline Low Tempernture Thermal Treatment & Indusurial and Municipal Landall & $\begin{array}{l}\text { VOCs (Bensene, Butanone, } \\
\text { Chloroform, Methylpentanone, TCE, } \\
\text { and Tobuene) }\end{array}$ \\
\hline Low Temperature Thermal Treatment & $\begin{array}{l}\text { Manufacsuring and Electroplating of } \\
\text { Plane Parts }\end{array}$ & VOC, (TCE and PCE) \\
\hline Low Tempenture Thermal Treaument & Former Dye Manufecturing Plant & VOCs (BTX) \\
\hline $\begin{array}{l}\text { Low Temperature Theraal Bxtraction } \\
\text { (Teciuk Procen) }\end{array}$ & Maribe Products Manufacturing & $\mathrm{PCB}$ \\
\hline $\begin{array}{l}\text { Therwad Draorption (Fure incimertion } \\
\text { of PCB Vapon) }\end{array}$ & Univertity Wautes & PCB: \\
\hline Low Teanperature Thermal Treatmeni & Aerospace Equipavent Manufieturer & voce \\
\hline
\end{tabular}




\section{DOE INTEGRATED DEMONSTRATIONS OF ENVIRONMENTAL TECHNOLOGIES:}

\section{GROUNDWATER AND SOIS CLEANUP}

Groundwater and Soil Cleanup Integrated Demonstrations seek to develop, demonstrate, evaluate, and compare characterization, assessment, and remediation technologies. These technologies span the cradle-to-grave requirements from characterization through remediation to closure and monitoring. Acceptance of demonstrated technologies by regulatory authorities and transfer of the technologies to other markets and applications are also objectives of the demonstrations.

Summaries of Groundwater and Soils Cleanup Integrated Demonstrations are included as follows:

- Cleanup of Volatile Organics in Saturated Soils and Groundwater.

- Cleanup of Plutonium-Contaminated Soil.

- Cleanup of Uranium-Contaminated Soil.

- Cleanup of Volatile Organics from Unsaturated Soils.

- Cleanup of Nonplutonium/Uranium Metals in Soils.

- Cleanup of Soils and Groundwater Containing Toxic Chemicals.

- Cleanup of Nonvolatile Organics in Unsaturated Soils.

- Cleanup of Nonvolatile Organics in Saturated Soils and Groundwater.

\section{WASTE RETRIEVAL AND WASTE PROCESSING}

Waste Retrieval and Waste Processing Integrated Demonstrations seek to develop, test, evaluate, and transfer new technologies required to characterize and remediate:

- radioactive and mixed waste currently being generated and stored in underground tanks and burial sites,

- toxic metals and organic chemicals in Resource Conservation and Recovery Act (RCRA) wastes, and

- structures and equipment prior to modernization or closure.

Summaries of Waste Retrieval and Waste Processing Integrated Demonstrations are included as follows:

- Buried Waste.

- Underground Storage Tanks.

- Newly Generated Mixed Waste.

- RCRA Waste Treatment.

- Combustible Waste.

- Decontamination and Decommissioning of Concrete Structures.

- Decontamination and Decommissioning of Metal Structures and Materials.

- In Situ Vitrification.

- Advanced Processing. 


\section{WASTE MINIMIZATION}

The Waste Minimization Integrated Demonstrations seek to develop, test, evaluate, and transfer technologies that:

- conserve, substitute, and recycle expensive and hazardous materials throughout the nuclear weapons complex and research and development laboratories;

- reduce the amount of radioactive material disposed of as waste;

- reduce air emissions of chlorinated hydrocarbons; and

- reduce risks to production workers and the costs of production.

Summaries of Waste Minimization Integrated Demonstrations are included as follows:

- Depleted Uranium Waste Minimization at the Oak Ridge Y-12 Plant.

- Plutonium Waste Minimization at Rocky Flats.

- Environmentally Conscious Electronics Manufacturing.

- Defense Programs/Office of Environmental Restoration and Waste Management Memorandum of Understanding.

- DOE/Air Force Memorandum of Agreement.

- Nonradioactive Components Manufacturing.

- General Waste Minimization. 


\section{AIR FORCE ENVIRONMENTAL TECHNOLOGY DEVELOPMENT}

The following are examples of the Air Force efforts in the development of environmental technologies to meet key operational needs. This is a very small illustrative list and does not represent the complete Air Force effort.

- Spray casting system, to replace conventional electroplating.

- Vapor emission control equipment and alternative cleaning process.

- Alternative non-cyanide stripping solutions

- IWTP volatile organic compounds air purification/emission control process

- Centrifugal/solvent extraction metals treatment process to selectively recover metals from IWTP influent

- Jet engine $\mathrm{NO}_{\mathbf{x}}$ emissions treatment process.

- Process to recycle/recover aqueous and non-aqueous chloroflurocarbon replacements.

- Enhanced air stripping with catalytic oxidation.

- Standardized monitoring equipment and protocol for measurement of toxic compounds. 


\section{ARMY ENVIRONMENTAL TECHNOLOGY DEVELOPMENT}

The following are some examples of the Army efforts in the development of environmental technologies to meet key operational needs. This is a very small illustrative list and does not represent the complete Army effort.

- Technology for geophysical measurement for hazardous waste sites.

- Composting of explosive-contaminated soils.

- Treatment of explosives-contaminated groundwater.

- In situ biotreatment of explosives-contaminated soils.

- Microbiology and degradation of explosives and energetics.

- Biological treatment of metals-contaminated groundwater.

- Technologies for treatment of metals-contaminated soils.

- In situ biotreatment of organics-contaminated soils.

- Development of new test methods for soils and groundwater.

- Environmental hazard assessment models. 
APPENDD $\mathrm{C}$

REFERENCES 


\section{REFERENCES}

1. ADF 617 023, "FY 92 Civil Engineering and Environmental Quality Technology Area Plan."

2. DOE/S-0078P, "Environmental Restoration and Waste Management -. Five-Year Plan, Fiscal Years 1992-1996." June, 1990.

3. Rivera, Rafael G. and Rachel Peterson, "Concept Paper: Environmental Quality Information Analysis Center (EQLAC)," October, 1990.

4. DOE/S-0090P, "Environmental Restoration and Waste Management ... Five-Year Plan, Fiscal Years 1993-1997," August, 1991.

5. EPA/540/2-91/001, Number 2, Innovative Treatment Technologies: Semi-Annual Status Report, September, 1991.

6. EPA/540/8-91/009, "Synopses of Federal Demonstrations of Innovative Site Remediation Technologies," May, 1991.

7. EPA/540/8-91/007, "Bibliography of Federal Reports and Publications Describing Alternative and Innovative Treatment Technologies For Corrective Action and Site Remediation, "May, 1991.

8. EPA/540/8-91/008, "Accessing Federal Data Bases for Contaminated Site Clean-Up Technologies," May, 1991. 
APPENDDX D

ORGANIZATIONS CONTACTED FOR EQLAC PLAN INPUT 
Martin Marietta Energy Systems

HAZWRAP

Tri-County Mall

Oliver Springs, TN 37840

HQ AFCESA/RD

Building 1120

Tyndall AFB, FL 32403-8001

Office of Technology Development

Department of Energy

Travion II

Washington DC 20585-0002

Division of Building Materials

and Structure

Department of Energy

1000 Independence Avenue, SW

Washington DC 20585

Oak Ridge National Laboratory

Bethel Valley Road

Oak Ridge, TN 37831-6205

Environmental Protection Agency

Office of Ground Water and Drinking Water

Mail Code WH 550

401 M Street, N.W.

Washington, DC 20460

Environmental Protection Agency

Solid Waste

Mail Code OS 311

401 M Street, N.W.

Washington, DC 20460

Technology Innovation Office

Office of Solid Waste and

Emergency Response

Environmental Protection Agency

401 M Street, SW

Washington DC 20585
Compliance Division/Office of Environment

Office of New production Reactors

Room 1 H072

Department of Energy

1000 Independence Avenue

Washington DC 20585

Office of Planning and Analysis

Conservation and Renewable Energy

Department of Energy

1000 Independence Ave

Washington DC 20585

Construction Management NP-3

New Production Reactors

Department of Energy

Environmental Modeling and

Simulation Team

USA CERL

P.O. Box 9005

Champaign, IL 61826

Supportability Investment Decision

Analysis Center

WRDC/TXL

Wright Patterson AFB, OH 45433

MLAC, CIAC, and HTMLAC

Purdue University 


\section{INTERNAI DISTRIBUTION}
1. D. R. Baumgardner
2. V. M. Bolinger
3. B. L. Bush
4. J. B. Cannon
5. E. D. Copenhaver
6-25. S. Das
26. S. B. Floyd
27. P. S. Gillis
28. C. R. Kerley
29. M. A. Kuliasha
30. D. P. Lombardi

31. P. M. Love

$\begin{aligned} \text { 31. } & \text { P. M. Love } \\ \text { 32. } & \text { V. C. Mei } \\ \text { 33. } & \text { R. R. Parks } \\ \text { 34. } & \text { D. E. Reichle } \\ \text { 35. } & \text { R. B. Shelton } \\ \text { 36. } & \text { T. J. Wilbanks } \\ \text { 37. } & \text { ORNL Patent Office } \\ \text { 38. } & \text { Central Research Library } \\ \text { 39. } & \text { Document Reference Section } \\ \text { 40-42. } & \text { Laboratory Records } \\ 43 . & \text { Laboratory Records-RC }\end{aligned}$

\section{EXTERNAL DISTRIBUTTON}

44. Michael T. Barainca, Energy Information Administration, U.S. Department of Energy, EM-50, Trerion II, Washington, DC 20585

45. B. G. Buchanan, Computer Science Department, University of Pittsburgh, 206 Mineral Industries Building, Pittsburgh, PA 15260

46. J. J. Cuttica, Vice President, End Use, Research and Development, Gas Research Institute, 8600 W. Bryn Mawr Avenue, Chicago, IL 60631

47. Charles F. Holt, Ph.D., Director, Engineering and Environmental Technology, Midwest Research Institute, 425 Volker Boulevard, Kansas City, MO 64110.

48. " Kathleen E. Main, Energy Information Administration, U.S. Department of Energy, EM50, Trerion II, Washington, DC 20585

49-58. Major Howard R. Meyer, Jr., Chief, R\&D Branch HQ AFCESA/RD, Building 1120, Tyndall AFB, FL 32403-8001

59. D. E Morrison, 333 Oxford Road, East Lansing, MI 48823

60. M. Williams, Professor, Department of Economics, Northern Illinois University, DeKalb, IL 60115

61. Office of Assistant Manager for Energy Research and Development, DOE-ORO, P.O. Box 2001, Oak Ridge, TN 38831-8600

62-71. OSTI, US. Department of Energy, P.O. Box 62, Oak Ridge, TN 37831 

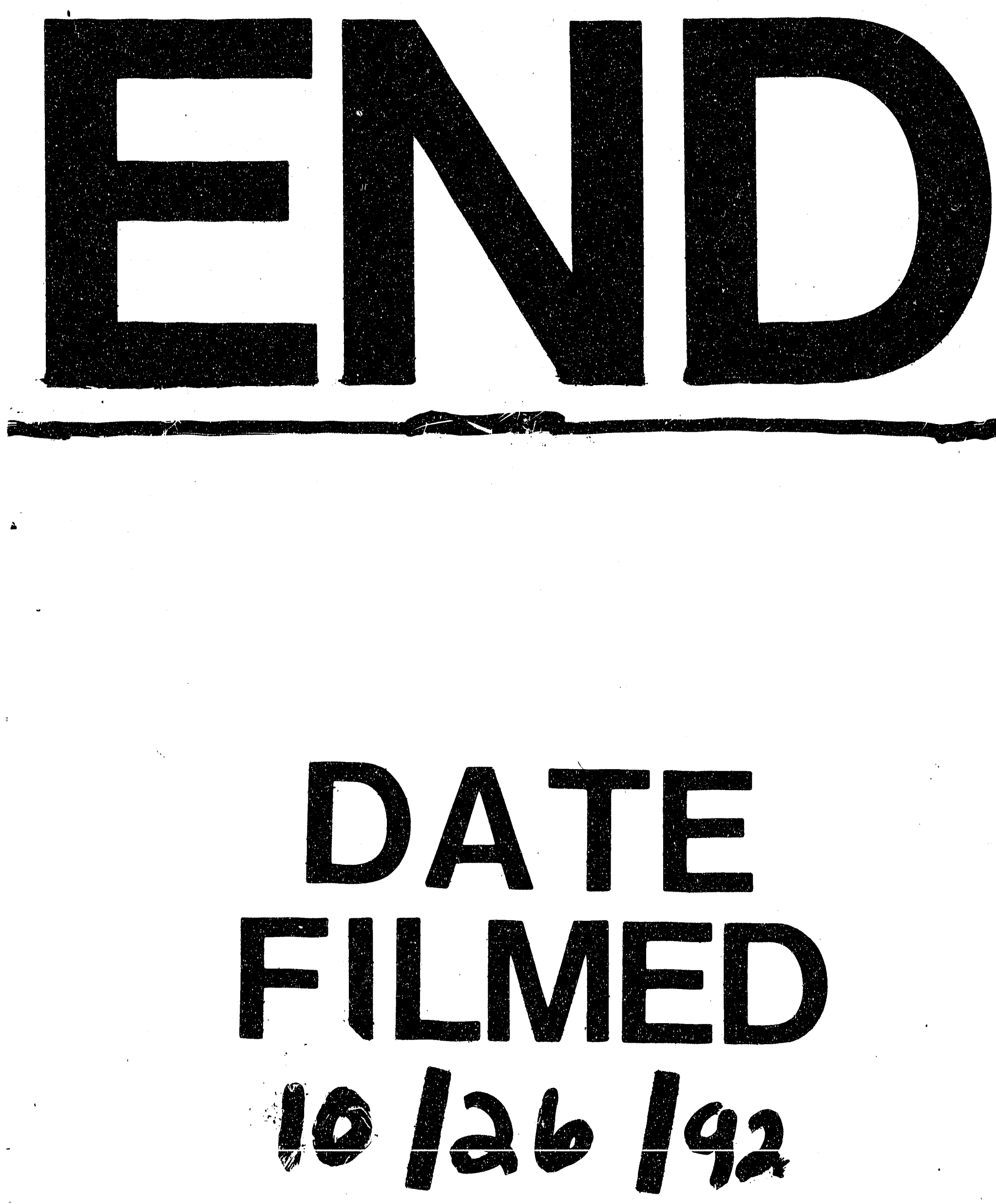
